\title{
polymers
}

ISSN 2073-4360

www.mdpi.com/journal/polymers

Review

\section{Cellulosic Bionanocomposites: A Review of Preparation, Properties and Applications}

\author{
Gilberto Siqueira $^{1,2}$, Julien Bras ${ }^{1}$ and Alain Dufresne ${ }^{1, *}$
}

1 The International School of Paper, Print Media and Biomaterials (Pagora), Grenoble Institute of Technology, BP 65 - 38402 Saint Martin d'Hères Cedex, France;

E-Mails: Gilberto.Siqueira@1tu.se (G.S.); Julien.Bras@grenoble-inp.fr (J.B.)

2 Division of Manufacturing and Design of Wood and Bionanocomposites, Luleå University of Technology (LTU) - SE - 97187 Luleå, Sweden

* Author to whom correspondence should be addressed;

E-Mail: Alain.Dufresne@ pagora.grenoble-inp.fr; Fax: 33-(0)4-76-82-69-33;

Tel: 33-(0)4-76-82-69-95.

Received: 9 October 2010; in revised form: 29 October 2010 / Accepted: 8 December 2010 /

Published: 13 December 2010

\begin{abstract}
Cellulose is the most abundant biomass material in nature. Extracted from natural fibers, its hierarchical and multi-level organization allows different kinds of nanoscaled cellulosic fillers - called cellulose nanocrystals or microfibrillated cellulose (MFC) - to be obtained. Recently, such cellulose nanoparticles have been the focus of an exponentially increasing number of works or reviews devoted to understanding such materials and their applications. Major studies over the last decades have shown that cellulose nanoparticles could be used as fillers to improve mechanical and barrier properties of biocomposites. Their use for industrial packaging is being investigated, with continuous studies to find innovative solutions for efficient and sustainable systems. Processing is more and more important and different systems are detailed in this paper depending on the polymer solubility, i.e., (i) hydrosoluble systems, (ii) non-hydrosoluble systems, and (iii) emulsion systems. This paper intends to give a clear overview of cellulose nanoparticles reinforced composites with more than 150 references by describing their preparation, characterization, properties and applications.
\end{abstract}


Keywords: cellulose nanocrystals; cellulose whiskers; microfibrillated cellulose; bio-nanocomposites

\section{Introduction to Natural Fibers and Cellulosic Nanofillers}

\subsection{Natural Fibers}

According to the Food and Agricultural Organization (FAO), each year farmers harvest around 35 million tons of natural fibers from a wide range of plants and animals. These fibers are used to form fabrics, ropes and twines, which have played a fundamental role in the human societies since the dawn of civilization. Natural fibers play an important role in supporting the world's population and allowing communication with paper and packaging. Some newer industrial uses have also been developed and are found to be promising. Moreover, income derived from the sale and export of natural fibers contributes to food security and poverty alleviation. With a desire to focus the world's attention on the role of such raw materials, the FAO declared 2009 as the International Year of Natural Fibers [1]. The world production and average cost of the main sources of natural fibers over the period ranging from 2003 to 2005 are summarized in Table 1. This corresponds to a global production of around 32 million tons and generates costs of over 36 million US dollars. Except for cotton and jute, all cellulosic natural fibers sources have a lower and rather similar production rate. However, it is worth noting that the production cost per ton is really different when compared to sisal and flax, for instance. The tonnage and geographical production is also different. Asia and South America are the most important producers with a large variety of fibers. For example, around 199 thousand tons of sisal are produced each year in Brazil compared to other natural fibers such as jute, ramie, curauá and rice fibers [2].

The term "natural fibers" is used to designate numerous kinds of fibers that are naturally produced by plants, animals and minerals [5]. To avoid any possible misunderstanding, it is important to clarify that in our case, 'natural fibers' are related to 'plant fibers'; also called 'vegetable fibers', 'lignocellulosic fibers', or 'cellulosic fibers' [2]. More specifically, this work is focused on 'annual plants', that include hairs (cotton, kapok), fibers-sheafs of dicotylic plants or vessel-sheafs of monocotylic plants, i.e., bast (flax, hemp, jute, ramie) and hard fibers (sisal, henequen, coir) [5].

Natural fibers are basically constituted of cellulose, lignin and hemicellulose. Pectin, pigments and extractives can be found in lower quantities. For this reason, natural fibers are also referred to as cellulosic or lignocellulosic fibers. The chemical composition and cell structure of natural fibers are quite complicated. Each fiber is essentially a composite in which rigid cellulose microfibrils are embedded in a soft matrix mainly composed of lignin and hemicellulose [6,7].

The properties of cellulosic fibers are strongly influenced by many factors e.g., chemical composition, internal fiber structure, microfibril angle, cell dimensions and defects, which differ from different parts of a plant as well as from different plants [8]. The mechanical properties of natural fibers also depend on their cellulose type, because each type of cellulose has its own crystalline organization, which can determine the mechanical properties [5]. As shown in Table 2, the chemical composition of natural fibers varies according to their origin. 
Table 1. Estimated global production and costs of natural fibers (2003-2005).

\begin{tabular}{|c|c|c|c|c|c|}
\hline \multirow{2}{*}{ Natural Fibers } & \multirow{2}{*}{ Main Producers Countries } & \multicolumn{2}{|c|}{ World Production } & \multicolumn{2}{|c|}{ Production Costs } \\
\hline & & Million Tons & $\%$ & Million US\$ & $\%$ \\
\hline \multicolumn{6}{|l|}{ Cellulosic } \\
\hline Cotton & China, USA, India, Pakistan, Uzbekistan, Brazil & 25.00 & 78.8 & 31.20 & 85.8 \\
\hline Jute & India, Bangladesh & 2.70 & 8.5 & 0.48 & 1.3 \\
\hline Flax & China, France, Belgium, Belarus, Ukraine & 0.08 & 0.2 & 0.43 & 1.2 \\
\hline Kenaf & Asian Countries & 0.50 & 1.6 & n.a. & n.a. \\
\hline Coir & $\begin{array}{l}\text { India, Sri Lanka, } \\
\text { Thailand, Malaysia }\end{array}$ & 0.45 & 1.4 & n.a. & n.a. \\
\hline $\begin{array}{l}\text { Sisal, Henequen and } \\
\text { other Agaves }\end{array}$ & $\begin{array}{l}\text { Brazil, Tanzania, China, } \\
\text { Kenya, Mexico }\end{array}$ & 0.30 & 0.9 & 0.08 & 0.2 \\
\hline Ramie & China & 0.15 & 0.5 & 0.17 & 0.5 \\
\hline Abaca & Philippines, Equator & 0.08 & 0.3 & 0.03 & 0.1 \\
\hline Hemp & $\begin{array}{c}\text { China, Spain, Korea, } \\
\text { Russian Federation, Chile }\end{array}$ & 0.09 & 0.3 & 0.03 & 0.1 \\
\hline Wool & Australia, China, New Zealand & 2.20 & 6.9 & 2.96 & 8.1 \\
\hline Silk & China, India & 0.14 & 0.4 & 0.98 & 2.7 \\
\hline Other animal fibers* & & 0.03 & 0.1 & n.a. & n.a. \\
\hline Total & & 31.72 & 100 & 36.35 & 100 \\
\hline
\end{tabular}

*Other animal fibers include alpaca, cashmere, angora, mohair, and camel. Source: FAO Statistics [3] and Moir et al. [4]. n.a.: not available.

Table 2. Chemical composition of some lignocellulosic fibers.

\begin{tabular}{|c|c|c|c|c|c|c|}
\hline \multirow[b]{2}{*}{ Fiber } & \multicolumn{2}{|c|}{ Holocellulose (wt\%) } & \multirow{2}{*}{$\begin{array}{l}\text { Lignin } \\
(w t \%)\end{array}$} & \multirow{2}{*}{$\begin{array}{c}\text { Ash } \\
(\text { wt\%) }\end{array}$} & \multirow{2}{*}{$\begin{array}{l}\text { Extractives } \\
\quad(w \mathrm{t} \%)\end{array}$} & \multirow[b]{2}{*}{ Ref. } \\
\hline & Cellulose (wt\%) & $\begin{array}{l}\text { Hemicellulose } \\
\text { (wt } \%)\end{array}$ & & & & \\
\hline \multirow{2}{*}{ Sugar Cane Bagasse } & \multicolumn{2}{|c|}{$71.1-84.9$} & \multirow{2}{*}{$24.3-25.3$} & \multirow{2}{*}{1.1} & \multirow{2}{*}{$0.7-3.5$} & \multirow{2}{*}[2,9]{} \\
\hline & $54.3-55.2$ & $16.8-29.7$ & & & & \\
\hline \multirow{2}{*}{$\begin{array}{c}\text { Leaflets of Phoenix } \\
\text { Dactilyfera Palm }\end{array}$} & \multicolumn{2}{|c|}{59.5} & \multirow{2}{*}{27} & \multirow{2}{*}{6.5} & \multirow{2}{*}{2} & \multirow{2}{*}{ [10] } \\
\hline & 33.5 & 26 & & & & \\
\hline \multirow{2}{*}{$\begin{array}{l}\text { Rachis of Phoenix } \\
\text { Dactilyfera Palm }\end{array}$} & \multicolumn{2}{|c|}{72} & \multirow{2}{*}{14} & \multirow{2}{*}{2.5} & \multirow{2}{*}{6} & \multirow{2}{*}{ [10] } \\
\hline & 44 & 28 & & & & \\
\hline \multirow{2}{*}{ Jute } & \multicolumn{2}{|c|}{82.1} & \multirow{2}{*}{15.9} & \multirow{2}{*}{1} & \multirow{2}{*}{ - } & \multirow{2}{*}[11,12]{} \\
\hline & 60 & 22.1 & & & & \\
\hline \multirow{2}{*}{ Cotton Lintners } & \multicolumn{2}{|c|}{96} & \multirow{2}{*}{-} & \multirow{2}{*}{ - } & \multirow{2}{*}{0.40} & \multirow{2}{*}[2]{} \\
\hline & 90 & 6 & & & & \\
\hline
\end{tabular}

In the present review, attention will be focused on cellulose nanocrystals or nanofibrils extracted from bleached cellulosic fibers. Firstly, it is important to detail the organization and structure of the cellulose within these fibers.

\subsection{Cellulose}

Cellulose is considered to be the most abundant renewable polymer on Earth [13]. This structural material is naturally organized as microfibrils linked together to form cellulose fibers. It is 
biosynthesized by a number of living organisms ranging from higher to lower plants, some amoebae, sea animals, bacteria and fungi [14].

Cellulose consists of a linear homopolysaccharide composed of $\beta$-D-glucopyranose units linked together by $\beta$-1-4-linkages [15]. The basic chemical structure of cellulose is presented in Figure 1. Each monomer bears three hydroxyl groups. It is therefore obvious that these hydroxyl groups and their ability to form hydrogen bonds play a major role in directing the crystalline packing and also governing the physical properties of cellulose [16].

Figure 1. Basic chemical structure of cellulose showing the cellobiose repeat unit.

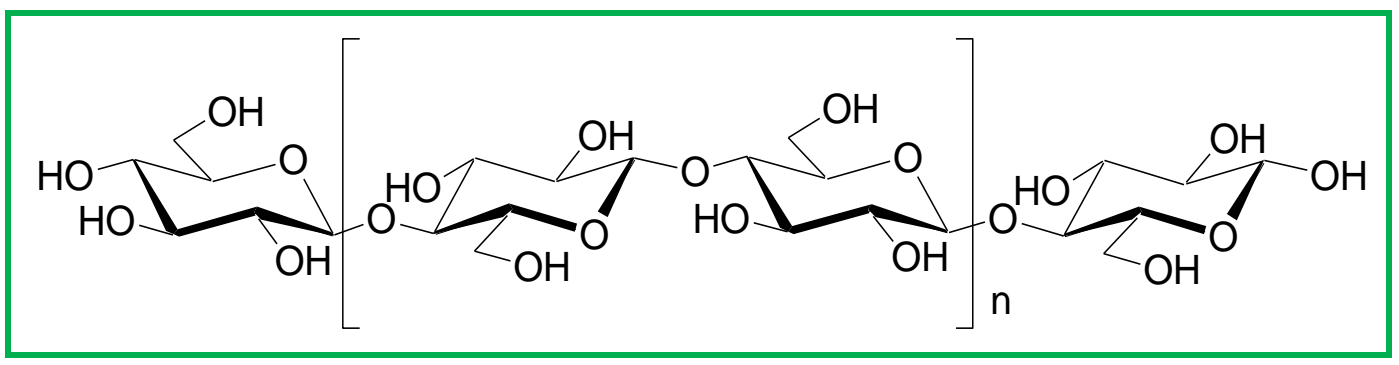

According to Sjoström [17], native cellulose in wood has a degree of polymerization (DP) of approximately 10,000 glucopyranose units and it is around 15,000 for native cellulose in cotton. However, Bledzki and Gassan [5] showed that purification procedures usually reduce the DP, e.g., a DP of 14,000 in native cellulose can be reduced to about 2,500. As reported by Daniel [18], valonia fibers present a DP of 26,500, while cotton fibers present a DP ranging from 20,000 to 14,000 depending on the part of the fiber where the analysis is performed. It is therefore important to keep in mind that the length of polymer chains varies according to the source of cellulose or even to the part of the plant.

The cellulose microfibril is the basic structural component of cellulose, formed during the biosynthesis. Actually, the chains of poly- $\beta-(1 \rightarrow 4)$-D-glucosyl residues aggregate to form a fibril, which is a long thread-like bundle of molecules laterally stabilized by intermolecular hydrogen bonds [19-21], as shown in Figure 2. Individual cellulose microfibrils have diameters ranging from 2 to $20 \mathrm{~nm}[22,23]$. Each microfibril can be considered as a string of cellulose crystals linked along the microfibril axis by disordered amorphous domains [22], e.g., twists and kinks [24].

Infra-red spectroscopy and x-ray diffraction studies of cellulose organization in plants have shown that the main portion of cellulose is constituted by crystallites with interspersed amorphous regions of low degree of order [18]. Native cellulose, namely cellulose I, is the crystalline cellulose. The term regenerated cellulose, also called cellulose II, is used to refer to cellulose precipitated out of solutions, generally alkali solutions $[13,18]$. These represent the two main polymorphs of cellulose. The current knowledge on the crystallography and biosynthesis of cellulose strongly suggests that the structure of cellulose is made up of parallel chains [25,26], whereas the crystalline structure of cellulose II is described as antiparallel [26-28]. Cellulose I is not the most stable form of cellulose. An additional hydrogen bond per glucose residue in cellulose II makes this allomorph the most thermodynamically stable form [28]. 
Figure 2. Scheme of the cellulose cell wall and microfibril organization [29].

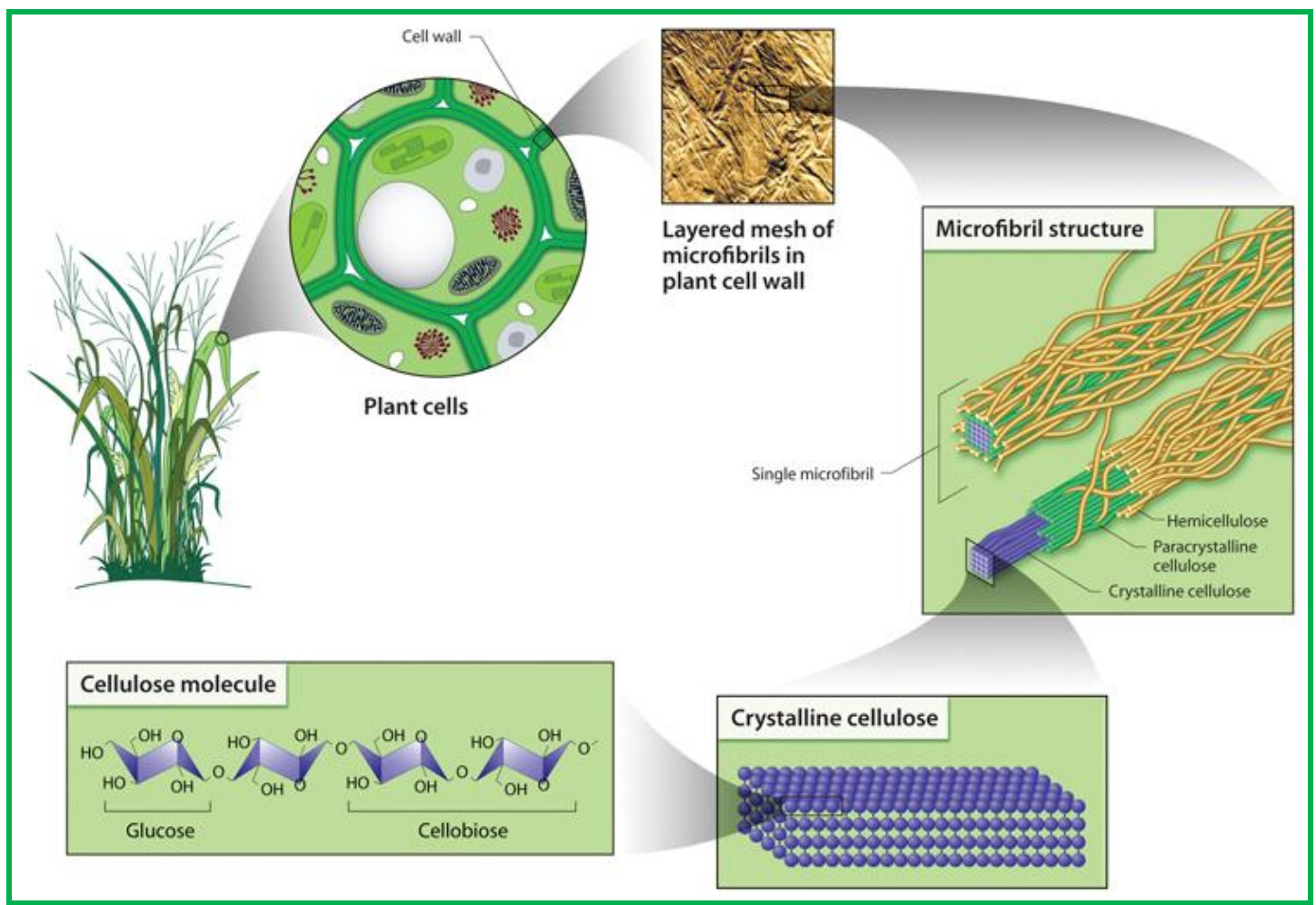

The transformation of cellulose I to cellulose II is a subject of interest of many studies despite the fact that Mercer discovered this transformation in 1850, when submitting native cellulose to a treatment with strong alkali. The mechanism of this transformation was a topic of intense debate that still continues. The existence of two different crystalline forms in native cellulose, $\mathrm{I}_{\alpha}$ and $\mathrm{I}_{\beta}$, was first demonstrated by Attala and VanderHart [30] from nuclear magnetic resonance (NMR) experiments with cross polarization/magic angle spinning (CP-MAS). The existence of such forms was also confirmed by electron diffraction and Fourier transform infrared spectroscopy (FTIR) analyses performed on algal cellulose during the study of the polymorphism of native cellulose by Sugiyama et al. [26]. Attala and VanderHart [30] proposed that most native celluloses are mixtures of cellulose $\mathrm{I}_{\alpha}$ and $\mathrm{I}_{\beta}$, solving a long time problem in the scientific community. The triclinic $\mathrm{I}_{\alpha}$ allomorph is predominant in algal-bacterial celluloses, while the monoclinic $\mathrm{I}_{\beta}$ form is the allomorph present in the cellulose typical from annual plants (ramie and cotton) [13]. Some physical properties of cellulose fibers depend on the ratio of these two allomorphs [28].

It was discovered that the structural forms $\mathrm{I}_{\alpha}$ and $\mathrm{I}_{\beta}$ can be found not only within the same cellulose sample [31], but also along a given microfibril [32].

Cellulose $I_{\alpha}$ is a metastable form and can be converted into the $I_{\beta}$ form by an annealing treatment $[28,32]$. In these two lattices, i.e., $\mathrm{I}_{\alpha}$ and $\mathrm{I}_{\beta}$, the conformation of the polysaccharide chains is similar although the hydrogen-bonding pattern is different [33]. Nishiyama et al. [34] reported that tunicin, the cellulose from tunicate — a sea animal — consists of nearly pure (around 90\%) $\mathrm{I}_{\beta}$ phase. On the contrary, freshwater alga Glaucocystis sp. consists of nearly pure (around 90\%) $\mathrm{I}_{\alpha}$ cellulose. There are several different crystalline arrangements of cellulose. Each one presents a distinctive diffraction pattern. These polymorphs of cellulose are denoted cellulose I, II, III $\mathrm{IIII}_{\mathrm{II}}, \mathrm{IV}_{\mathrm{I}}$ and $\mathrm{IV}_{\mathrm{II}}$ and they can be inter-converted depending on the chemical treatment and source [13,27]. 
The material used for cellulose nanofiller is native cellulose (cellulose I) extracted by traditional bleaching treatments of lignocellulosic fibers. Cellulose I is responsible for mechanical properties due to its high modulus and crystallinity. Moreover, nanosized fillers have been found to be very promising reinforcing elements since about 15 years.

There are basically two families of nanosized cellulosic particles. The first one consists of cellulose nanocrystals and the second one is microfibrillated cellulose (MFC) [8,13,35]. However, different terminologies are used to describe these cellulose nanoparticles, leading to some misunderstanding and ambiguities. These terminologies, as well as sources of raw cellulosics and extraction processes, are summarized in Table 3.

Table 3. The different terminologies used to describe cellulose nanoparticles.

\begin{tabular}{|c|c|c|c|c|}
\hline Acronyms & Name & Source & Process & Reference \\
\hline \multirow{5}{*}{$\mathrm{CNW}$} & \multirow{5}{*}{ Cellulose nanowhiskers } & Ramie & $\mathrm{H}_{2} \mathrm{SO}_{4}$ hydrolysis & [36] \\
\hline & & $\mathrm{MCC}$ & $\mathrm{H}_{2} \mathrm{SO}_{4}$ hydrolysis & [37] \\
\hline & & MCC & $\mathrm{H}_{2} \mathrm{SO}_{4}$ hydrolysis & [38] \\
\hline & & Grass fiber & $\mathrm{H}_{2} \mathrm{SO}_{4}$ hydrolysis & [39] \\
\hline & & $\mathrm{MCC}$ & LiCl:DMAc & {$[40]$} \\
\hline \multirow{6}{*}{ CNXL } & \multirow{6}{*}{ Cellulose Nanocrystals } & \multirow{2}{*}{ Cotton Whatman filter paper } & \multirow{2}{*}{$\mathrm{H}_{2} \mathrm{SO}_{4}$ hydrolysis } & [41] \\
\hline & & & & {$[42]$} \\
\hline & & Bacterial cellulose & $\mathrm{H}_{2} \mathrm{SO}_{4}$ hydrolysis & [43] \\
\hline & & Cotton (cotton wool) & $\mathrm{H}_{2} \mathrm{SO}_{4}$ hydrolysis & [44] \\
\hline & & MCC & $\mathrm{H}_{2} \mathrm{SO}_{4}$ hydrolysis & {$[45]$} \\
\hline & & $\mathrm{MCC}$ & Sonication & {$[46]$} \\
\hline CNW-HCl & Cellulose nanowhiskers & Cotton linters & $\mathrm{HCl}$ hydrolysis & [47] \\
\hline $\mathrm{Wh}$ & Whiskers & Cellulose fibers & $\mathrm{H}_{2} \mathrm{SO}_{4}$ hydrolysis & {$[8,48]$} \\
\hline NF & Nanofibers & Wheat straw & $\begin{array}{c}\mathrm{HCl}+\text { Mechanical } \\
\text { Treatment }\end{array}$ & [49] \\
\hline NCC & Nanocrystalline cellulose & $\mathrm{MCC}$ & $\mathrm{H}_{2} \mathrm{SO}_{4}$ hydrolysis & {$[50]$} \\
\hline \multirow{3}{*}{ MFC } & \multirow{3}{*}{$\begin{array}{l}\text { Microfibrillated } \\
\text { Cellulose }\end{array}$} & Pulp Gaulin & Homogenizer & [51] \\
\hline & & Pulp Daicel & - & {$[52]$} \\
\hline & & Pulp Daicel & - & [53] \\
\hline NFC & $\begin{array}{c}\text { Nanofibrillated cellulose } \\
\text { Cellulose nanofibrils }\end{array}$ & Sulfite pulp & Mechanical & {$[54,55]$} \\
\hline $\mathrm{MCC}$ & $\begin{array}{l}\text { Microcrystalline } \\
\text { cellulose }\end{array}$ & Alpha-cellulose fibers & Hydrolysis & {$[56]$} \\
\hline- & Cellulose Crystallites & Cotton Whatman filter paper & $\mathrm{H}_{2} \mathrm{SO}_{4}$ hydrolysis & [57] \\
\hline- & Nanocellulose & Sisal fibers & $\mathrm{H}_{2} \mathrm{SO}_{4}$ hydrolysis & [58] \\
\hline- & Cellulose Microcrystal & Cotton Whatman filter paper & $\mathrm{HCl}$ hydrolysis & [59] \\
\hline- & Nanofibers & Soybean pods & $\begin{array}{c}\text { Chemical treatment }+ \\
\text { high pressure defibrilator }\end{array}$ & [60] \\
\hline
\end{tabular}

The main steps involved in the preparation of cellulose whiskers and MFC are presented in Figure 3.

The raw fibers are first milled and then submitted to alkali and bleaching treatments with $\mathrm{NaClO}_{2}$. These steps allow elimination of lignin and hemicelluloses, while leaving cellulose moieties intact if 
optimal conditions are respected. The bleached fibers are then ready to be hydrolyzed (acid hydrolysis treatment) or disintegrated (mechanical shearing at high pressure).

Figure 3. The main steps involved in the preparation of cellulose nanoparticles.

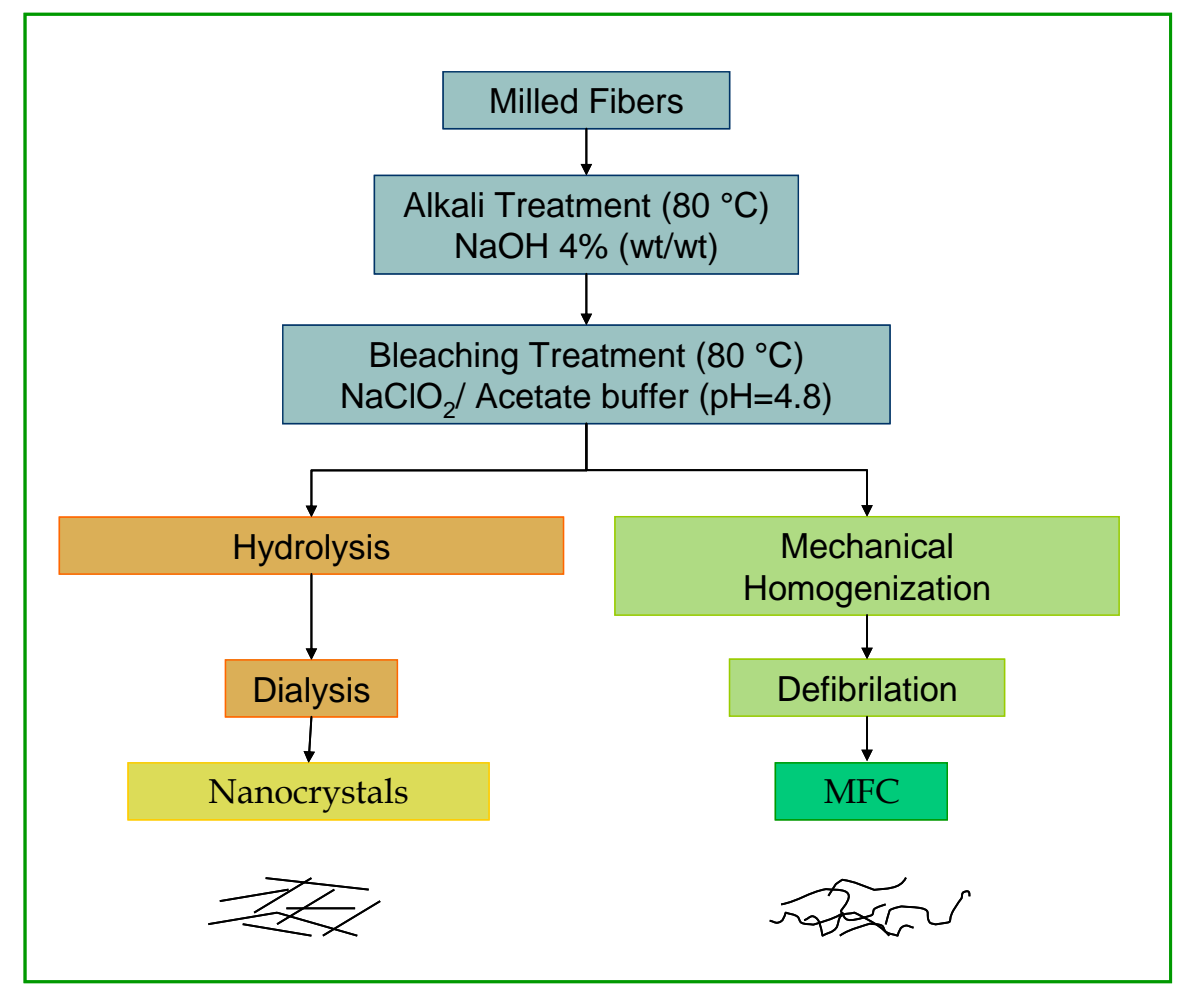

\subsection{Cellulose Whiskers}

The extraction of crystalline cellulosic regions, in the form of nanowhiskers, is a simple process based on acid hydrolysis. Azizi Samir et al. [22] described cellulose whiskers as nanofibers which have been grown under controlled conditions that lead to the formation of high-purity single crystals. As described in Table 3, many different terms have been used in the literature to designate these rod-like nanoparticles. They are mainly referred to as "whiskers" or cellulose nanocrystals. The terms microfibrils, microcrystals or microcrystallites are also used, despite their nanoscale dimensions [13]. A recent review from Habibi et al. [61] gives a clear overview of such cellulosic nanomaterials.

As previously discussed, cellulose fibers and microfibrils do not display a regular surface. This means that apart from crystalline domains, cellulose also occurs in a non-crystalline state (amorphous). The cellulose amorphous regions are randomly oriented in a spaghetti-like arrangement leading to a lower density compared to nanocrystalline regions $[28,33]$. The equatorial positions of the glucopyranose residues stabilize the structure of cellulose, increasing its rigidity and resulting in extensive intra and intermolecular hydrogen bonding that also causes insolubility in water [62]. On the other hand, the amorphous regions are susceptible to acid attack and, under controlled conditions, they may be removed leaving crystalline regions intact $[33,62]$.

Beck-Candanedo et al. [63] mentioned Rånby and Ribi as the pioneers in the production of stable suspensions of colloidal-sized cellulose crystals by sulfuric acid hydrolysis of wood and cotton cellulose in 1949. De Souza Lima and Borsali [33] described the principle of the disruption of the 
amorphous regions of cellulose in order to produce cellulose nanocrystals. The hydronium ions can penetrate the material in these amorphous domains promoting the hydrolytic cleavage of the glycosidic bonds releasing individual crystallites.

Dong et al. [64] were among the first researchers to study the effect of hydrolysis conditions on the properties of resulting cellulose nanocrystals. They proved that longer hydrolysis time leads to shorter monocrystals and also to an increase in their surface charge.

Beck-Candanedo et al. [63] also studied the properties of cellulose nanocrystals obtained by hydrolysis of softwood and hardwood pulps. They studied the influence of hydrolysis time and acid-to-pulp ratio in order to obtain cellulose nanocrystals. They explained that the reaction time is one of the most important parameters to be considered in the acid hydrolysis of wood pulp. Moreover, they reported that too long reaction times completely digest the cellulose to yield its component sugar molecules. On the contrary, lower reaction times will only yield large undispersable fibers and aggregates. The effect of the reaction conditions on cellulose nanocrystal surface charge and sulfur content was not significant and was controlled by factors other than hydrolysis conditions. However, chiral nematic pitch decreases when increasing the cellulose concentration and decreasing the nanocrystals length.

Dufresne [13] reported that the stability of nanocrystal suspensions depends on the dimensions of their dispersed particles, their size polydispersivity and their surface charge. Araki et al. [65] compared the effects of using sulfuric acid or hydrochloric acid to produce stable suspensions of cellulosic nanocrystals. They explained that sulfuric acid provides more stable aqueous suspensions than hydrochloric acid. According to the same authors, hydrochloric acid produced cellulose nanocrystals with minimum surface charge. On the contrary, sulfuric acid-prepared nanocrystals present a negatively charged surface [13], due to the esterification of surface hydroxyl groups to give charged sulfate groups [63]. More recently, Angellier et al. [66] evaluated similarly the influence of sulfuric and hydrochloric acids on the hydrolysis of starch. In agreement with the previous studies, they reported that the use of sulfuric acid not only reduces the possibility of agglomeration of starch nanocrystals, but also limits their flocculation in aqueous medium.

Even though the process of acid hydrolysis of cellulosic material is considered to be a well-known process, Bondeson et al. [45] considered it necessary to optimize the process to produce a high-yield aqueous stable colloid suspension of cellulose whiskers. They stipulated that large quantities of whiskers suspensions are required to be used as nanoreinforcement in biopolymers. Investigating the optimization process of microcrystalline cellulose (MCC) hydrolysis, a response surface methodology was used to evaluate the variation of the following parameters: concentration of MCC, sulfuric acid concentration, duration and temperature of hydrolysis, as well as duration of the sonication step. The same authors emphasized the importance of time and temperature of hydrolysis together with the sulfuric acid concentration as important single factors in the process of preparation of negatively charged isolated cellulose whiskers in water. Cellulose whiskers with a length ranging between 200 and $400 \mathrm{~nm}$ were obtained by using a $63.5 \mathrm{wt} \%$ sulfuric acid concentration for approximately $2 \mathrm{~h}$ and with a yield of $30 \%$.

Cellulose whiskers can be prepared from a variety of sources, e.g., microcrystalline cellulose [45], bacterial cellulose [67], algal cellulose (valonia) [68], hemp [69], tunicin [70,71], cotton [62], 
ramie [36], sisal [72], sugar beet [73], and wood [63]. Transmission electron micrographs of some cellulose nanocrystals are presented in Figure 4.

Figure 4. Transmission electron micrographs from diluted suspensions of hydrolyzed (a) tunicin [74], (b) ramie [36], (c) cotton [57], (d) sugar beet [73], (e) MCC [75], and (f) bacterial cellulose [43].

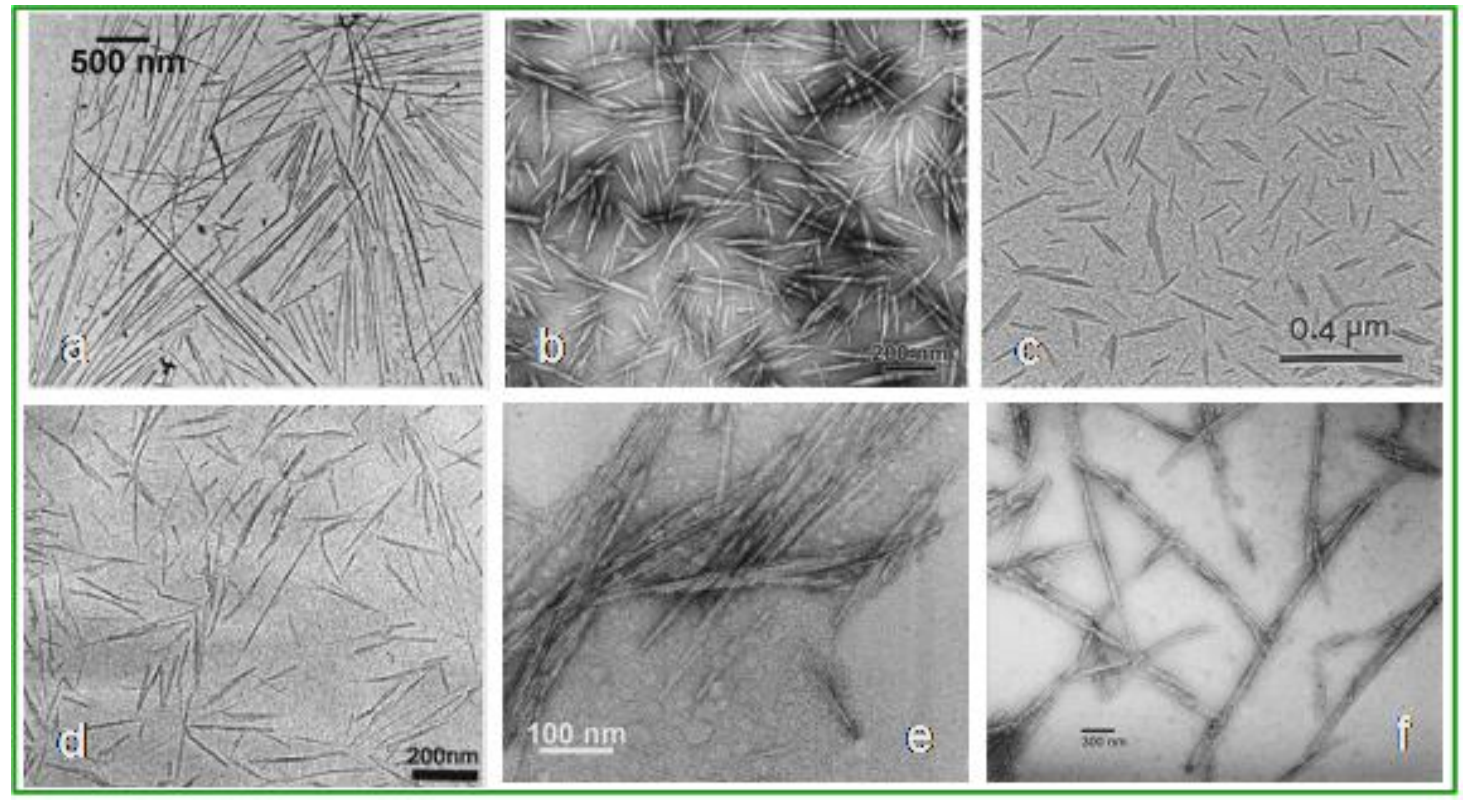

To a certain extent, geometrical characteristics such as size, dimensions and shape of cellulose nanocrystals depend on the nature of the cellulose source as well as the hydrolysis conditions such as time, temperature, ultrasound treatment, and purity of materials [13,22,63]. Above a critical concentration, the rod-like shape of the charged cellulose nanocrystals leads to the formation of an anisotropic liquid crystalline phase [63,64]. Nevertheless, typical dimensions of whiskers range from 5 to $10 \mathrm{~nm}$ in diameter and from 100 to $500 \mathrm{~nm}$ in length. Specific values are provided later.

Since the cellulose whiskers are devoid of chain folding, they contain only a small number of defects. Their Young's modulus was determined by different authors to be between $130 \mathrm{GPa}$ [76] and $250 \mathrm{GPa}$ [77]. This is close to the modulus of the perfect crystal of native cellulose. The experimental strength was assessed to be of the order of $10 \mathrm{GPa}$ [22].

\subsection{Microfibrillated Cellulose}

Cellulose microfibrils extracted by a mechanical disintegration process from wood cell was first obtained by Herrick et al. [78], and Tubark et al. [79], in 1983. This new type of cellulosic material was named microfibrillated cellulose (MFC). MFC can be viewed as a cellulosic material, composed of expanded high-volume cellulose, moderately degraded and greatly expanded in surface area, obtained by a homogenization process [80].

Contrary to straight cellulose whiskers, cellulose microfibrils are long and flexible nanoparticles. MFC is composed of more or less individualized cellulose microfibrils, presenting lateral dimensions in the order of 10 to $100 \mathrm{~nm}$, and length generally in the micrometer scale [19,35], and consisting of alternating crystalline and amorphous domains. Another noteworthy difference between these two 
kinds of nanoparticles is that MFC presents a web like structure [23]. Very recently, researchers have managed to evaluate the elastic modulus of single cellulosic microfibrils using atomic force microscopy (AFM). They proposed a value of 145.2 $\pm 31.3 \mathrm{GPa}$ for microfibrils prepared by TEMPOoxidation and $150.7 \pm 28.8 \mathrm{GPa}$ for microfibrils produced by acid hydrolysis [81].

In the 1980s, different research groups [78,79] reported MFC as a low-cost and totally new form of cellulose. It has a large surface area as result of heat and mechanical action. In these studies, the authors worked with a Gaulin homogenizer, model 100-KF3-8BS, using a pressure of 8,000 psi. Cooling was used to maintain a product temperature in the range of $70-80{ }^{\circ} \mathrm{C}$ during the homogenization treatment. Initially, the wood pulp was precut to reduce the fiber length to $0.6-0.7 \mathrm{~mm}$. After repeated homogenization treatments, they obtained a diluted dispersion of MFC, having a gel-like appearance.

Another piece of equipment appeared as an alternative to the use of the Gaulin homogenizer. The microfluidizer from Microfluidics Inc., USA, is a piece of equipment that also allows the defibrillation of cellulosic pulps. The fiber suspension is led through thin $\mathrm{z}$-shaped chambers under high pressure. Pressure can reach levels as high as 30,000 psi. When the pressurized product enters in the interaction chamber and passes through geometrically fixed microchannels, very high velocities are achieved. At that point, two primary forces act in the product stream. One of the forces occurs as a result of product stream with the channel walls at high velocity. The shear results in a deformation of the product stream. The other is produced by the impact of the high velocity stream upon itself. At the end of the process a heater exchanger returns the product stream to ambient temperature.

With either equipments-Gaulin homogenizer or microfluidizer-it is necessary to repeat the procedure of homogenization several times, in order to increase the degree of fibrillation [78,82]. Nakagaito et al. [83] indirectly evaluated the degree of fibrillation of kraft pulp by water retention, measured as moisture content after centrifuging a 2 wt $\%$ fiber suspension of treated pulp slurry at $1,000 \mathrm{G}$ for $15 \mathrm{~min}$. The fiber slurry was passed through a high pressure homogenizer 2, 6, 14, 22, and 30 times. They observed that the disintegration could be improved by increasing the number of passes to 30 times. It is not difficult to conclude that a higher number of passes results in an increased energy necessary for the disintegration.

Pretreatments have been developed by some researchers in order to solve the problem of energy consumption during the process. This is one of the main drawbacks related to the process of MFC production. A European project (SUNPAP, FP7) is aimed at scaling up the MFC process for industrial applications. The target application is packaging.

Zimmerman et al. [77] applied an acid hydrolysis step before pumping the sulfite pulp through the homogenizer. In their experiments, $5 \mathrm{~g}$ of oven dried pulp were hydrolyzed by $200 \mathrm{~mL}$ of sulfuric acid $(10 \mathrm{wt} \%)$ under stirring at $60{ }^{\circ} \mathrm{C}$ for $16 \mathrm{~h}$. After centrifugation and washing steps, the suspension was neutralized with sodium hydroxide $(0.1 \mathrm{M})$. Finally, the suspension was homogenized with a microfluidizer (M-100Y High Pressure Pneumatic Microfluidic Processor, Newton, MA). The sulfuric acid treatment, combined with mechanical dispersion, resulted in finer fibril structures than MFC obtained only by a mechanical treatment. The former produced diameters below $50 \mathrm{~nm}$, but their lengths were still in the micrometer range.

Another treatment that has been used in combination with mechanical shearing is enzymatic hydrolysis. Henriksson et al. [82] treated cellulosic wood fiber pulps with pure C-type endoglucanase in order to facilitate the disintegration of MFC. Hydrochloric acid was also used as a pretreatment step. 
In their work, these authors used an endoglucanase manufactured by Novozymes A/S Denmark. They considered the enzymatic treatment as an environmentally friendly process since it did not involve solvents or chemical reactants. The MFC obtained by enzymatically pretreated pulps showed more favorable structures, with higher aspect ratio than MFC resulting from acid hydrolysis treatment. However, they demonstrated that a high concentration enzymatic treatment can increase the extent of fine material and reduce the fiber length. An increasing fiber swelling in water was observed due to the enzymatic treatment.

Similar studies were carried out by the group of Ankerfors et al. [84]. First, sulfite pulp was refined to increase the accessibility of the cell wall for subsequent enzymatic treatment with endoglucanase (Novozym 476, Novozymes North America Inc., Franklinton, NC). The enzymatic treatment was done at $50{ }^{\circ} \mathrm{C}$ for $2 \mathrm{~h}$. The concentration was $0.17 \mu \mathrm{L}$ of monocomponent endoglucanases per gram fiber $(5 \mathrm{ECU} / \mu \mathrm{L})$. After stopping the enzymatic treatment, the material was passed through the microfluidizer (Microfluidics M-110EH Microfluidizer Processor, Newton, MA). Additionally, the diameter of the interaction chamber was varied by changing the interaction chamber. They first passed the slurry through chambers of 400 and $200 \mu \mathrm{m}$ three times, and then five times through a chamber pair of 200 and $100 \mu \mathrm{m}$. The operation pressures were 105 and $170 \mathrm{MPa}$, respectively. They highlighted the importance of milder hydrolysis provided by enzymatic treatment. Compared to the more aggressive acid hydrolysis treatment, the enzymatic treatment yielded longer and highly entangled nanoscale fibrils. They demonstrated that the enzymatic hydrolysis step avoids blocking problems during the homogenization treatment. Finally, the enzymatic step leads to reduced energy consumption allowing widespread use of the material and an industrial pilot is being built in their laboratory since May 2010.

Saito et al. $[85,86]$ have proposed a new process to obtain MFC based on TEMPO reaction and strong mixing. In their study [86], individualized MFC was obtained by TEMPO-mediated oxidation at room temperature and stirring at $500 \mathrm{rpm}$. They determined that at $\mathrm{pH} 10$, optimal conditions were reached, giving cellulose nanofibers with 3-4 $\mathrm{nm}$ in width and a few microns in length.

Tubark et al. [79] and Herrick et al. [78] suggested a wide range of potential commercial uses for MFC in the earliest 80s. They proposed some applications, e.g., in foods, cosmetics, paints, paper and nonwoven textiles, oils field services, and medicine. Recently, because of its properties such as high strength, flexibility and aspect ratio, many research groups have focused their attention on the use of MFC as a reinforcing phase in nanocomposites.

\section{Bionanocomposites}

\subsection{Nanocomposites Definition}

The term "nano" is used to designate nanometer scale items $\left(10^{-9} \mathrm{~m}\right)$. A nanometer is, therefore, equivalent to the billionth of a meter, or 80,000 times thinner than a human hair. The nanometer range covers sizes bigger than several atoms but smaller than the wavelength range of visible light [87]. An increasing interest from the scientific community to work with materials in nanometric scale has been observed since the introduction of the concept of nanotechnology by Richard Feynman in 1959 at a meeting of the American Chemical Society [88]. However, nanocomposite materials have been widely 
studied for only about the past 20 years [89]. This new generation of nanostructured hybrid materials, constitutes a new class of materials named nanocomposites. Currently, polymer nanocomposites are defined as polymers containing fillers with at least one dimension smaller than $100 \mathrm{~nm}[8,40,87]$.

Contrary to traditional composites, polymer nanocomposites generally involve low content of well-dispersed nanofillers. The main reason is that it is not necessary to fill the polymer with high quantities of filler to achieve high mechanical properties. In other words, the nanoparticles are generally considered as excellent opportunities for the development of high-performance multifunctional composites.

The components of a nanocomposite material can be constituted of inorganic/inorganic, inorganic/organic or organic/organic sources [90]. The recent resurgence of interest in nanocomposites is related to several reasons. The first one is the significant industrial impact related to the possibility to design and create new materials and structures with unprecedented flexibility and physical properties. Secondly, nanoscale fillers are almost free of defects and their application in the composite area opens a window of opportunity to overcome the limitations of traditional micrometer scale. Finally, due to the high specific surface area, nanocomposites present a large volume of interfacial matrix material (interphase) with properties different from those of the bulk polymer. A uniform dispersion of nanoparticles leads to a very large matrix-filler interfacial area, changing the molecular mobility, relaxation behavior and ensuing thermal and mechanical properties [91,92].

In recent times, more attention has turned towards understanding and exploiting the unique physical properties of polymer nanocomposites. This increasing interest can be ascribed to a growing recognition that moves beyond formulating polymers with nanoparticular fillers, and towards really engineered, designed, and functional nanocomposites.

One drawback related to a more extensive development of polymer nanocomposites for advanced applications is a limited ability to predict properties. Despite the existence of techniques to tailor the surface chemistry and structure of the nanoparticles, the impact of the nanoscale filler surface on the morphology, dynamics, and properties of the surrounding polymer chains is not easily predicted from classical models [92]. The second point discusses the impact of nanoparticles on human health. Several researchers are working on this subject and some European projects (e.g., NanoFun) are trying to understand the main phenomena involved. This polemic is important and it is mainly due to some previous health problems (e.g., asbestosis) but also because the term nanoparticles is not clearly defined. Indeed, only one dimension below $100 \mathrm{~nm}$ is used to classify the nanoparticles, whereas their shape and chemical surface seem to be important. A new European legislation on nano element and food contact is under evaluation since 2010. Other recent works have been published in Canada regarding the toxicity of cellulose nanocrystals and first results are positive [93]. In this review, the issue of toxicity will not be discussed because of a lot of uncertainty. Discussion will be focused on the improvement of mechanical properties.

Bionanocomposites are bio-based nanocomposites. Actually, they represent an emerging group of nanostructured hybrid materials. Expanding the concept of biocomposites [94] to the nanostructured hybrid materials, "bionanocomposites" can be defined in the following two ways. It could designate nanocomposites as materials made from renewable nanoparticles (e.g., cellulose whiskers and MFC) and petroleum-derived polymers like PP, PE, and epoxies. However, nanocomposites derived from 
biopolymers (e.g., PLA and PHA) and synthetic or inorganic nanofilers (e.g., carbon nanotubes and nanoclay) also come under "bionanocomposites" [40,95].

\subsection{Cellulose Based Nanocomposites}

The use of cellulose nanoparticles (e.g., whiskers and MFC) as reinforcement in nanocomposites is a relatively new area of interest. Besides the low cost of the raw material, the use of cellulosic particles as a reinforcing phase in nanocomposites has numerous well-known advantages e.g., low density; renewable nature; wide variety of filler available through the world; low energy consumption; high specific properties; modest abrasivity during processing; biodegradability; relatively reactive surface, which can be used for grafting specific groups and almost unlimited availability [22,96-100]. For reinforcement applications, cellulose nanoparticles present some disadvantages, for instance, high moisture absorption, poor wetability, incompatibility with most of polymeric matrices and limitation of processing temperature. Indeed lignocellulosic materials start to degrade near $220{ }^{\circ} \mathrm{C}$ restricting the type of matrix that can be used in association with natural fillers [22,101].

The recent developments on cellulosic nanoparticles as a reinforcing phase in nanocomposite films led to a broad literature devoted to nanocellulose that becomes a topical subject. According to the SciFinder literature research system, scientific papers on "cellulose and nano" have increased from 57 papers for the year 2000 to more than 700 in 2009, with a cumulative total of 517 papers in 2000 and 4,062 papers in September 2009.

A group in France [71,102] is considered as the first to report the preparation of cellulose whiskers based nanocomposites. Until today, their research is considered as a very important work in the field of cellulose based polymer nanocomposites because it demonstrated the reinforcing potential of high aspect ratio cellulose nanocrystals. Fifteen years ago, they successfully prepared nanocomposites with a uniform dispersion and high mechanical properties at very low nanofillers' grade [71].

One drawback related to the use of cellulose whiskers for polymer nanocomposites is their inherent difficulty to disperse in non-polar medium, because of their polar surface [40]. In other words, the incorporation of cellulose nanocrystals as a reinforcement material has so far been mainly limited to aqueous or polar environments. Two main different techniques can be used to prepare polysaccharides nanocomposite films [13], namely:

- Water or organic solvent evaporation by solvent casting;

- Extrusion with freeze-dried cellulose nanoparticles.

The first technique is the most commonly used, and three systems can be distinguished depending on the polymer used as matrix, i.e., (i) water soluble polymers, (ii) polymer emulsions, and (iii) non hydrosoluble polymers.

Concerning the last case, two routes can be envisaged in order to obtain non-flocculated dispersions of cellulose nanocrystals in an appropriated organic medium [87]:

i. Coating of the surface of the cellulose nanocrystals with surfactants having polar heads and long hydrophobic tails;

ii. Grafting of hydrophobic chains at the surface of cellulose nanocrystals. 
These procedures allow the preparation of polymer nanocomposites by mixing the nanoparticle suspensions in organic medium with a solution of polymer.

The second way to obtain cellulose nanoparticles reinforced nanocomposites is a melting compounding technique (extrusion method) [40]. This is one of the most recent methods used to prepare such kind of nanocomposites, and not many studies have been carried out in this area yet. Therefore, it goes without saying that the possibility to scale up the laboratory work to industrial scale starts to be more realistic [40]. In this case, the main issue is to work with cellulose nanoparticles in the dry state. Indeed, as soon as these polysaccharides nanoparticles are dried, strong hydrogen bonds establish and most of the time aggregates are obtained limiting the nanosized reinforcement. It was demonstrated that nanocomposites prepared by casting and evaporating a mixture of cellulose whiskers and synthetic latex presented higher mechanical properties than nanocomposites of the same mixture prepared by freeze-drying and hot-pressing $[48,103]$. The very large reinforcing effect reported for cast and evaporated materials was ascribed to the formation of a rigid whisker/whisker network, probably linked by hydrogen bonds. It was suggested that the formation of this network is more predominant in the evaporated films due to lower processing times.

Figure 5 summarizes the different strategies used to prepare cellulose based-nanocomposites by casting technique.

Figure 5. General scheme of strategies used for preparation of cellulose based nanocomposites by solvent casting.

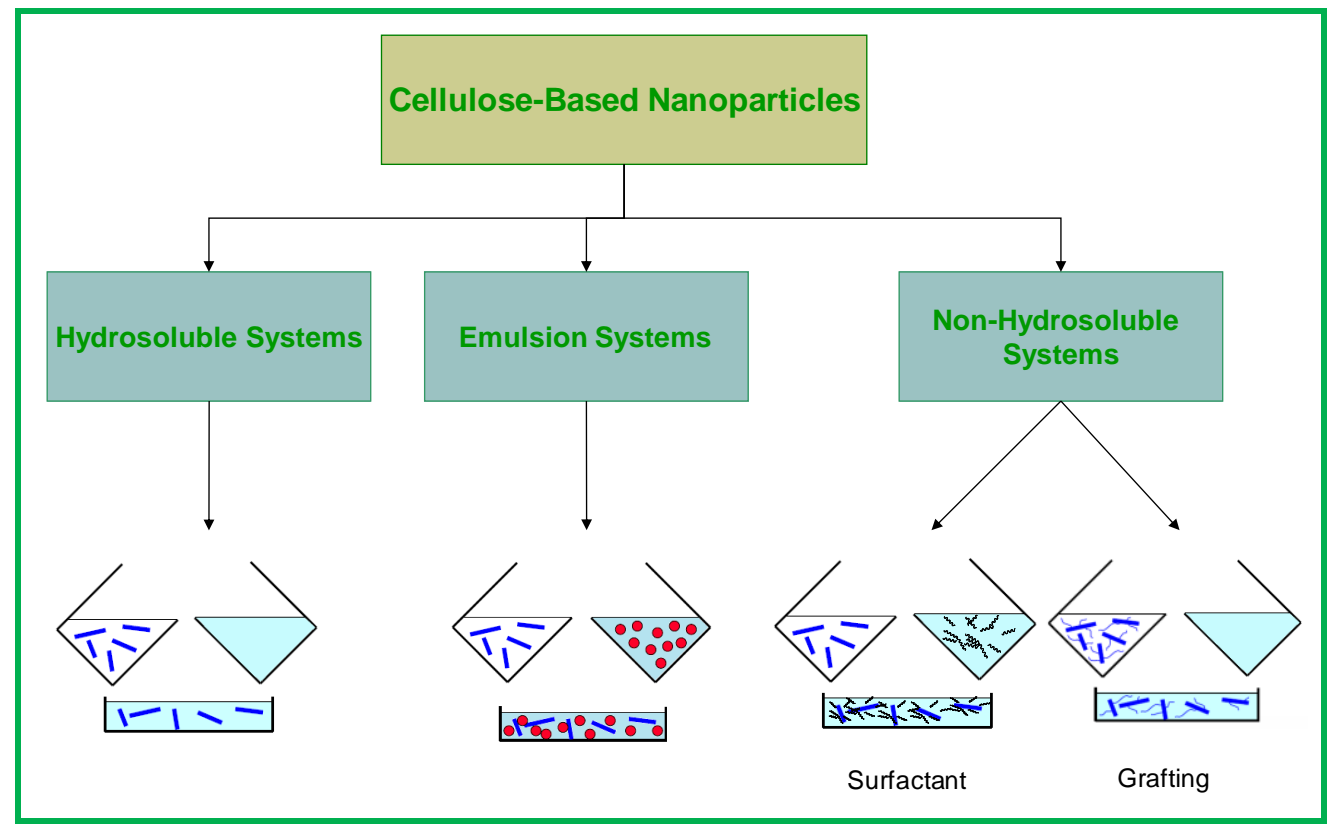

\subsubsection{Hydrosoluble Systems}

Cellulose whiskers are recovered in water suspension after acid hydrolysis. Because of the high stability of aqueous cellulose nanoparticle suspensions, water is the preferred medium for preparing nanocomposite films. It simply consists in mixing this suspension with the polymer previously dissolved in water, and evaporating the liquid. However, it restricts the choice of the matrix to hydrosoluble polymers. In addition, these polymers are inherently highly sensitive to humidity. 
Therefore, it is difficult to be sure whether there is no more water in the film after water evaporation which requires important attention. For example some researchers store their films in an oven and under vacuum. Storage of films under specific environments is also necessary as proved by works on polyvinyl acetate (PVA) [72,104,105], and hydroxypropylcellulose (HPC) [106]. Indeed, water induces a strong plasticizing effect and greatly affects the properties of the film [72].

\subsubsection{Emulsion Systems}

A first alternative to enlarge the range of polymer matrices consists in using the polymer in the form of latex. The main interest is to use non-polar and, therefore, non-water sensitive polymers while keeping an aqueous media for the processing of the films to preserve the dispersion of the nanoparticles.

In their pioneering work, Favier et al. [71,102] adopted the technique of solvent casting using a synthetic latex obtained by the copolymerization between styrene (35 wt \%) and butyl-acrylate (65 wt $\%)$ (poly $(\mathrm{S}-\mathrm{co}-\mathrm{BuA}))$. These authors mixed the whisker aqueous suspension with the polymer latex. The nanocomposite films were obtained by water evaporation and particle coalescence at room temperature, that is at a temperature higher than $\mathrm{T}_{\mathrm{g}}$ of poly $(\mathrm{S}-\mathrm{co}-\mathrm{BuA})$, around $0{ }^{\circ} \mathrm{C}$.

Afterwards, many research studies were done in order to process nanocomposites by using matrices such as poly ( $\beta$-hydroxyoctanoate) (PHO) [107,108], polyvinylchloride (PVC) [109-112], waterborne epoxy [113], natural rubber [10], and polyvinyl acetate (PVAc) [72]. In all these reports, the polysaccharide nanoparticles suspensions were dispersed with the polymer emulsion in aqueous medium.

\subsubsection{Non-Hydrosoluble Systems}

The use of surfactants with the aim to obtain a stable suspension of cellulose nanocrystals in organic media is a procedure used by different authors.

In 2002, Bonini et al. [70] described a procedure based on their previous patented experiments [114]. Following this procedure, the nanocrystal suspension of tunicin whiskers was initially prepared by an acid hydrolysis treatment based on the method of Marchessault et al. [115]. It was then mixed with the surfactant phosphoric ester of poly(ethylene oxide) (9) nonylphenyl (PEPNP) in a ratio of 4:1 by weight (PEPNP/cellulose whiskers). Pellets were obtained by freezing-drying the aqueous suspension [116]. The pellets were then dispersed in toluene and the excess surfactant eliminated by centrifugation and redispersion in toluene. This procedure can be used to prepare nanocomposites by dispersing the suspension of coated whiskers in a polymer solution in toluene.

Ljungberg et al. [117] prepared nanocomposites reinforced with tunicin whiskers and high molecular weight atactic polypropylene (aPP). In one set of experiments, the aqueous suspension of cellulose whiskers was mixed with a phosphoric ester of polyoxyethylene (9) nonylphenyl ether (BNA) at a ratio of 4:1 of BNA to cellulose. Using the same procedure described by Bonini et al. [70], they obtained a suspension of coated whiskers in toluene. The nanocomposite films were prepared by mixing solubilized atactic polypropylene in hot toluene $\left(110^{\circ} \mathrm{C}\right)$ with the whiskers previously dispersed in toluene. The solvent was evaporated overnight at $110{ }^{\circ} \mathrm{C}$ to avoid PP precipitation, and then it was kept under vacuum for $6 \mathrm{~h}$ to complete the evaporation of the solvent. Finally, the films 
were hot-pressed at $150{ }^{\circ} \mathrm{C}$ for 20 min under a pressure of $7 \mathrm{MPa}$. Nanocomposites with a high level of dispersion were obtained due to the use of the surfactant. It was observed that the mechanical behavior in the non-linear range was increased, especially the tensile strength of the nanocomposites compared to the neat matrix. Moreover, elongation at break remained unchanged. A similar study was performed using the same surfactant to prepare nanocomposites with isotactic polypropylene [118]. The nanocomposites obtained with surfactant-modified whiskers exhibited enhanced properties when compared to the neat matrix or to the composites containing other types of fillers. They also suggest the use of nanocomposites containing surfactant-modified cellulose whiskers at elevated temperature.

In 2007, Petersson et al. [37] coated cellulose whiskers, obtained by acid hydrolysis of microcrystalline cellulose (MCC), with the surfactant Beycostat A B09 in order to mix them with PLA. Cellulose whiskers were solvent exchanged to tert-butanol or t-butanol by centrifugation. The surfactant was added to the whisker suspension in tert-butanol in a proportion of $4: 1(\mathrm{w} / \mathrm{w})$. The suspension containing coated whiskers was freeze-dried and dispersed in chloroform with PLA. The nanocomposites were prepared by solvent casting at room temperature for one day, and then placed in a vacuum oven at $40{ }^{\circ} \mathrm{C}$ for two weeks in order to remove residual solvent. When nanocomposites of PLA and whiskers coated with surfactant were analyzed, it was suggested that the surfactant did not have access to single whiskers, but rather encapsulated several whiskers that were held together by hydrogen bonding. It was demonstrated that the large amount of surfactant used (20 wt $\%$ ) decreased the crystallinity and increased the porosity of the material. Moreover, the results of dynamical mechanical thermal analysis (DMTA) have shown that the surfactant used in this study had higher interaction with the matrix than with modified whiskers.

Therefore, this strategy is not promising; one important drawback is that high quantities of surfactant are required to obtain highly dispersed nanocrystal suspensions. In general, it is even several times higher than the quantity of cellulose whiskers. This is ascribed to the high specific area inherent to nanosized particles.

Working in another direction, Azizi Samir et al. [119] prepared polymer nanocomposites reinforced with cellulose whiskers by dispersing the whisker suspensions in an organic solvent, $\mathrm{N}, \mathrm{N}$-dimethylformamide (DMF), without any surface chemical modification or coating surfactant. In this experiment, the aqueous suspension of tunicin whiskers was freeze-dried and the resulting powder was dried for $48 \mathrm{~h}$ at $100{ }^{\circ} \mathrm{C}$ under vacuum. The dried whiskers were stored in a glovebox. Suspensions of tunicin whiskers in DMF were prepared by mixing dried whiskers with DMF until obtaining homogeneous suspensions. These suspensions were sonicated to produce individual whiskers. Nanocomposites based on unsaturated polyether were prepared by UV radiation curing in argon atmosphere at room temperature. The solvent was allowed to evaporate at $55{ }^{\circ} \mathrm{C}$ for $30 \mathrm{~h}$ in a glovebox and a mercury lamp was used for the cross-linking process.

Azizi Samir et al. [120] used the same procedure to prepare nanocomposites by dispersing cellulose tunicin whiskers suspension in DMF in a solution of a linear unsaturated polycondensate. The nanocomposites were prepared by adding a photoinitiator, 4-(2-hydroxyethoxy)phenyl-(2hydroxy-2propyl) ketone, as a cross-linking agent, followed by casting and solvent evaporation at $55^{\circ} \mathrm{C}$ for $30 \mathrm{~h}$ in a glovebox under an argon atmosphere. The mechanical and ionic conductive properties of composites were evaluated. It was demonstrated that composites containing tunicin whiskers, previously dispersed in organic solvent without chemical modification, presented higher mechanical 
properties at high temperatures when compared to the neat matrix. In addition, at higher temperatures, the ionic conductivity was almost composition-independent (Figure 6).

Figure 6. Arrhenius plot of the ionic conductivity for composite NPC400-LiTFSI $(\mathrm{O} / \mathrm{Li}=12)$ electrolytes cross-linked with $2 \mathrm{wt} \%$ HPPK and filled with $0(\diamond) ; 6(\bigcirc)$, and $10 \mathrm{wt} \%(\square)$ of tunicin whiskers and unfilled NP400-LiTFSI $(\mathrm{O} / \mathrm{Li}=12)$ electrolyte cross linked with 10\% HPPK ( $\boldsymbol{\nabla})$ [120].

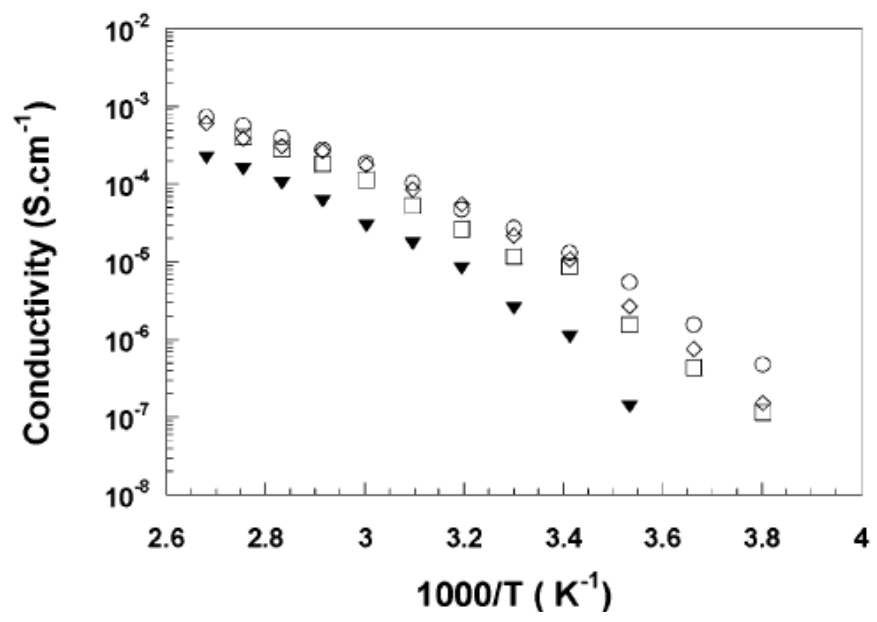

Viet et al. [121] studied the dispersion of cotton nanocrystals in dipolar aprotic solvents by sonication only. The aqueous suspensions of cotton whiskers were freeze-dried and mixed with the appropriate organic solvent (DMSO, DMF and formamide). The whisker content was varied in order to obtain dispersions of $1 \%$ and/or $3 \%(\mathrm{w} / \mathrm{v})$ concentration. The suspensions were sheared for $10 \mathrm{~min}$ and sonicated (Ultrasonic Processor VC 1500) for $3 \mathrm{~min}$ at $40 \%$ output control and then three times for $3 \mathrm{~min}$ at $80 \%$ output control using ice bath cooling with an Ultrasonic Processor (Model GE-50). The sonicated suspensions were filtered through a glass microfiber filter to minimize the presence of possible aggregates in the final suspension. Stable suspensions were obtained, but it was observed that a small amount of water $(0.1 \%)$ was necessary to stabilize the suspension of re-dispersed freeze-dried cellulose nanocrystals.

Another study presented by Van den Berg et al. [122] compared the dispersability of non-functionalized tunicin whiskers prepared by $\mathrm{HCl}$ hydrolysis ( $\mathrm{HCl}-\mathrm{TW})$ and negatively charged sulfate groups tunicin whiskers prepared by sulfuric acid hydrolysis $\left(\mathrm{SO}_{4}-\mathrm{TW}\right)$ in a series of polar protic and aprotic organic solvents. The aqueous suspensions of whiskers were freeze-dried and the resulting material was mixed with the appropriate solvent at a concentration of $1 \mathrm{mg} / \mathrm{mL}$. The solvent dispersion of whiskers was sonicated at, or slightly above room temperature for $6 \mathrm{~h}$. The quality of the dispersion was evaluated by its birefringence using two cross-polarizers (Figure 7).

Poorly dispersed samples were further sonicated and the final quality of the dispersion was evaluated by transmission electron microscopy. The authors determined that the presence of negatively charged sulfate ester moieties on the surface of the whiskers was the determining factor in the dispersability in polar aprotic solvents. Protic solvents, such as formic acid and m-cresol, were shown to effectively disrupt the hydrogen bonds between aggregated whiskers, dispersing even the non-charged HCl-TW. It was reported that dispersions of whiskers in organic solvents are valuable 
intermediates for nanocomposite preparation [122]. However, this preparation was stifled due to the lack of a common solvent/dispersant for polymer and whiskers. Indeed, in spite of the recognized evolution of whiskers dispersion in organic medium, it is worth noting that it is not always easy to disperse whiskers in a solvent in which the polymer studied is also soluble. Sometimes, surface chemical modification of cellulose nanocrystals is an inevitable step for their suspension in an organic solvent.

Figure 7. Birefringence phenomenon of lyophilized tunicin whiskers in different polar solvents. (a) In water (as it was prepared); or freeze-dried and re-dispersed in (b) water; (c) DMF; (d) DMSO; (e) N-methyl pyrrolidone; (f) formic acid, and (g) m-cresol [122].

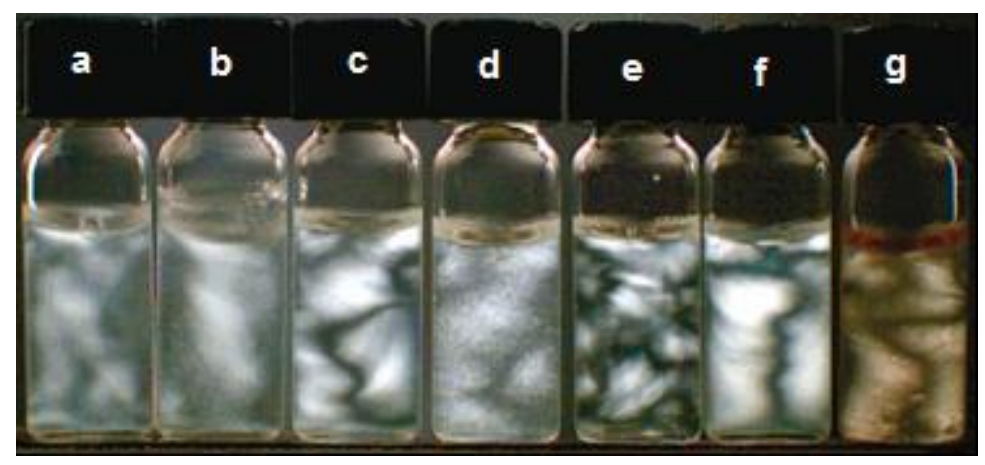

Indeed, surface chemical modification is another strategy that can be used to obtain stable dispersions of nanocrystals in organic solvents in which the required polymer is soluble. Moreover, it can improve the compatibility between the whiskers and the host matrix as already proven in the studies of fiber-based composites [123]. Furthermore, most of the results on surface chemical modification of cellulose related to fiber treatment and several strategies have already been detailed [97]. However, only very few and recent papers have been published on nanoscale cellulose treatment due to the recent development of such materials and their important differences in specific area compared to cellulose fibers.

Grafting of long chains can also be used to transform the nanofiller into a co-continuous material by increasing apolar character through grafting agents bearing a reactive end group and a long "compatibilizing" tail. This latter approach of surface modification can also allow processing nanocomposites by classical methods such as hot-pressing, injection molding or thermoforming.

The modification of cellulose nanocrystals and MFC with organic compounds via reaction of the surface hydroxyl groups has been carried out with different grafting agents such as isocyanates [124], anhydrides [124], chlorosilanes [125,126] or silanes [23,43,125]. The surface chemical modification of cellulose whiskers prepared from Halocynthia roretzi with different silyating agents such as isopropyldimethylchlorosilane (IPDM-SiCl), n-butylmethylchlorosilane (BDMSiCl), $n$-octyldimethylchlorosilane (ODMSiCl) and $n$-dodecyldimethylchlorosilane (DDMSiCl) were studied by Goussé et al. [125]. It was demonstrated that under optimal conditions, the surface silyated cellulose whiskers could be dispersed in organic solvents of medium polarity, such as acetone and THF. However, it was not possible to disperse them in solvents of very low polarity such as toluene or hexane. It was demonstrated that the stability and birefringence of whisker suspensions were 
dependent on the degree of substitution of the nanocrystals. The extent of silylation has to be limited to avoid a detrimental effect on the whiskers. The surfactant technique [116] appears somewhat superior than the silylation procedure to prepare stable cellulose whisker suspensions in very low polarity media.

Different coupling agents such as 3-aminopropylethoxysilane, 3-glycodoxypropyl-trimethoxysilane, and a titanate coupling agent (Lica 38) were used to modify the surface of MFC [23]. These surface chemical modifications changed the hydrophilic character of MFC to hydrophobic without affecting their crystalline structure. Modified MFC was incorporated into epoxy resin systems using acetone as a solvent. In order to prepare nanocomposites, the desired amount of epoxy was added to the MFC suspension in acetone. The system was sonicated for $5 \mathrm{~min}$ and stirred for 4-5 h. The composites were cured at $40{ }^{\circ} \mathrm{C}$ for $12 \mathrm{~h}$ and postcured at $120{ }^{\circ} \mathrm{C}$ for $2 \mathrm{~h}$. The evaporation of acetone occurred simultaneously with the curing process. The authors observed a higher dispersion level and stronger adhesion of modified MFC with the matrix and suggested the use of the same procedure to modify cellulose whiskers.

Araki et al. [59] prepared cellulose whiskers by acid hydrolysis with $\mathrm{HCl}$ of Whatman CF11 cellulose powder. The aqueous suspensions of nanocrystals were carboxylated by $\mathrm{NaClO}$ oxidation catalyzed by 2,2,6,6, -tetramethyl-1-(pyperidinyloxy) radical (TEMPO). The carboxylation of cellulose nanocrystals was followed by amidation with a single amidated PEG $\left(\mathrm{PEG}-\mathrm{NH}_{2}\right)$ using a water soluble carbodiimide (EDC). In this procedure, $400 \mathrm{~mL}$ of the carboxylated nanocrystals suspension containing between 0.5 and $1 \mathrm{wt} \%$ solid content was stirred until dissolution with PEG-NH $\mathrm{N}_{2}$. The former was added in two-times excess the equivalent estimated carboxyl content. The $\mathrm{pH}$ was adjusted to 7.5-8.0 and $20 \mathrm{~mL}$ of water containing EDC and an esterification reagent (NHS) was added. Observation under polarized microscopy was performed to determine the stability of the dispersion of carboxylated and PEG-grafted whiskers. Even after freeze-drying, the PEG-grafted whiskers were able to be redispersed in water and chloroform and showed birefringence and stability for several days. However, concerning the liquid crystal behavior, PEG-grafted nanocrystals did not show significant difference compared to ungrafted ones. The authors reported that it is necessary to use longer PEG molecules and to reduce the amount of carboxyl groups to improve the reaction conditions.

More recently, researchers have developed a new way of processing that allows chemical modification of polysaccharide nanocrystals with larger chains. This process consists in transforming polysaccharide nanocrystals into a co-continuous material to improve the interfacial adhesion between the filler and the matrix. Depending on the molecular weight, entanglements between grafted and ungrafted polymer chains can be obtained. Bionanocomposites can be prepared, from this procedure, by classical methods such as solvent casting, hot-pressing, extrusion, injection molding or thermoforming.

Habibi et al. [36] have grafted ramie nanocrystals with poly( $\varepsilon$-caprolactone) by a ring-opening polymerization technique. In this work, the aqueous suspension of ramie nanocrystals was solvent-exchanged to dry toluene by centrifugation and redispersion. The polymerization was performed under nitrogen atmosphere at $95{ }^{\circ} \mathrm{C}$. Using flaming-dried syringes, the monomer ( $\varepsilon$-caprolactone) was introduced in a two-neck flask, adding $\mathrm{Sn}(\mathrm{Oct})_{2}$ as catalyst, at weight ratio of 5:1. After $24 \mathrm{~h}$, the reaction was stopped by adding some drops of hydrochloric acid (1 M). Modified nanocrystals were stable in apolar solvents such as toluene even after $24 \mathrm{~h}$. This process appears as an 
important method of surface chemical modification that allows preparation of PCL-based nanocomposites with grafted poly( $\varepsilon$-caprolactone) chains at the surface of ramie nanocrystals. However, it is difficult to control the length of the grafted chains by this procedure, which can be a drawback for specific applications. Mechanical properties of grafted nanocrystals reinforced nanocomposites were improved compared to ungrafted ones.

The use of the ring-opening polymerization procedure was also performed by Lin et al. [127] to graft polycaprolactone (CW-g-PCL) onto linter nanocrystals. In this work, CW-g-PCL was prepared under microwave irradiation. Freeze-dried nanocrystals were put into an ampoule with the monomer ( $\varepsilon$-caprolactone) at a weight ratio of $1: 40$, nanocrystals to monomer. The catalyst used was $\operatorname{Sn}(\mathrm{Oct})_{2}$. The mixture was homogenized and vacuum-exhausted for $30 \mathrm{~min}$. It was submitted to microwave irradiation for $5 \mathrm{~min}$ and finally purified by dispersing the product in dichloromethane and precipitation in methanol. The PCL nanocomposites reinforced with modified nanocrystals were obtained by casting and dichloromethane evaporation.

In 2008, Lönnberg et al. [128] modified the surface of MFC extracted from wood pulp by grafting poly( $\varepsilon$-caprolactone) via ring-opening polymerization. MFC was mixed with $\varepsilon$-caprolactone (weight ratio of 1:10) into a one-necked flask under magnetic stirring. The dispersion was sonicated and benzyl alcohol was added as co-initiator. The temperature of the system was maintained at $95{ }^{\circ} \mathrm{C}$. $\mathrm{Sn}(\mathrm{Oct})_{2}$ was added to the system and kept under argon atmosphere as a catalyst. The resulting material was dispersed in THF, and unmodified MFC and monomer impurities were eliminated via filtration. The filtrate outcome was precipitated in methanol. Once again, modified nanoparticles (MFC) can be used as nanoreinforcing phase in polymer nanocomposites such as PCL, and many other matrices.

The surface chemical modification of cellulose nanocrystals via the grafting-from approach was studied by Morandi et al. [44]. Polystyrene chains were grafted on the surface of cotton nanocrystals via surface-initiated atom transfer radical polymerization (SI-ATRP). In this work, cotton nanocrystals were mixed with triethylamine and DMF under nitrogen atmosphere. By using 2-Bromoisobutyryl bromide as initiator, the reaction was carried out at $70{ }^{\circ} \mathrm{C}$ for $24 \mathrm{~h}$. Soxhlet extractions were used to purify the modified nanocrystals. The mixture was extracted for $24 \mathrm{~h}$ with dichloromethane and $24 \mathrm{~h}$ with ethanol. It was possible to control the character of the polymerization through kinetic study and following the homopolymer number-average molecular weight versus conversion. Despite the fact that these authors did not use the modified nanocrystals as reinforcement in a polymer matrix, this technique is very interesting since long chains modified nanocrystals were obtained under controlled conditions. However, it seems that, at least under the conditions presented in this work, the cellulose chemical modification via grafting-from technique changes partially the cellulose crystallinity.

In 2009, Berlioz et al. [129] developed a solvent-free method to modify the surface of cellulose nanocrystals and MFC through esterification with palmitoyl chloride. To achieve this modification, aerogels of tunicin whiskers were obtained by freeze-drying aqueous suspensions $(0.2 \% \mathrm{w} / \mathrm{v})$, and dehydrating suspensions of bacterial cellulose with $\mathrm{CO}_{2}$ under supercritical conditions. The suspension was solvent exchanged from water to ethanol and the reagent in large excess was evaporated and diffused into the cellulose nanoparticles. The pressure of the system was kept at $100 \mathrm{mbar}$ and a nitrogen stream was provided to eliminate hydrogen chloride formed during the ester reaction. Samples were purified through soxhlet extractions with acetone. High efficiency was reached by this method that allowed esterification of cellulose nanoparticles to different extents with fatty acid 
chlorides. The main advantage of this process is the absence of solvent. These modified nanoparticles can be potentially used as a reinforcing phase in polymer nanocomposites.

To conclude, there are several pathways to prepare cellulose based-nanocomposites. The surface chemical modification is a promising solution to obtain nanocomposites with a matrix of low polarity such as PCL or PLA. Now, since it was demonstrated that it is possible to prepare such materials, it is important to measure and know their properties.

\section{Properties of Cellulose-Based Nanocomposites}

\subsection{Mechanical Properties}

Cellulose nanoparticles such as whiskers and MFC possess a huge specific area and impressive mechanical properties, rendering both as serious potential candidates to improve mechanical properties of a neat matrix. Dynamical mechanical analysis (DMA) is presented as a powerful tool to investigate the linear mechanical behavior of nanocomposites in different temperature/frequency ranges. Classical tensile or compressive tests can be used to evaluate the non linear mechanical properties [13].

In the recent years, various studies have been developed with the aim to elucidate the origin of the mechanical reinforcing effect.

\subsubsection{Mechanical Modeling}

The unusually high reinforcing effect observed for cellulose whiskers reinforced nanocomposites motivated some researchers to investigate the modeling of their mechanical properties. Indeed, classical predicting models for short-fiber composites cannot be applied. The observed experimental values were much higher than those obtained from these classical models [71].

The mean-field approach on which the Halpin-Kardos model [130] is based is classically used to predict the mechanical behavior of short-fibers composites and semi-crystalline polymers. In this approach, the modulus and the geometry of the fibers are accounted for, but no interaction between the fibers are assumed [130]. Indeed, this model is based on the concept that the material is made of short fibers, homogeneously dispersed in a continuous matrix. In this approach, the composite is assimilated to a four plies laminate. Within each ply, the fibers are parallel to each other and the mutual orientations of the plies are $0^{\circ},+45^{\circ},+90^{\circ}$, and $-45^{\circ}$. The mechanical properties of each ply are derived from the micromechanical equations of Halpin-Tsai.

Finally, in order to explain the unusual data (high modulus values) of cellulose whiskers reinforced nanocomposites, the following phenomena were suggested: (i) strong interactions between whiskers, and (ii) a mechanical percolation effect.

By using the series-parallel model of Takayanagi et al. [131] (Figure 8) modified by Ouali et al. [132] to include the percolation approach, the mechanical behavior of these nanocomposites has been better understood.

In the scheme presented in Figure 8, $\mathrm{R}$ and $\mathrm{S}$ refer to the rigid (cellulosic filler) and soft (polymeric matrix) phases, respectively. $\psi$ corresponds to the volume fraction of the percolating rigid phase. 
Figure 8. Schematic representation of the series parallel model.

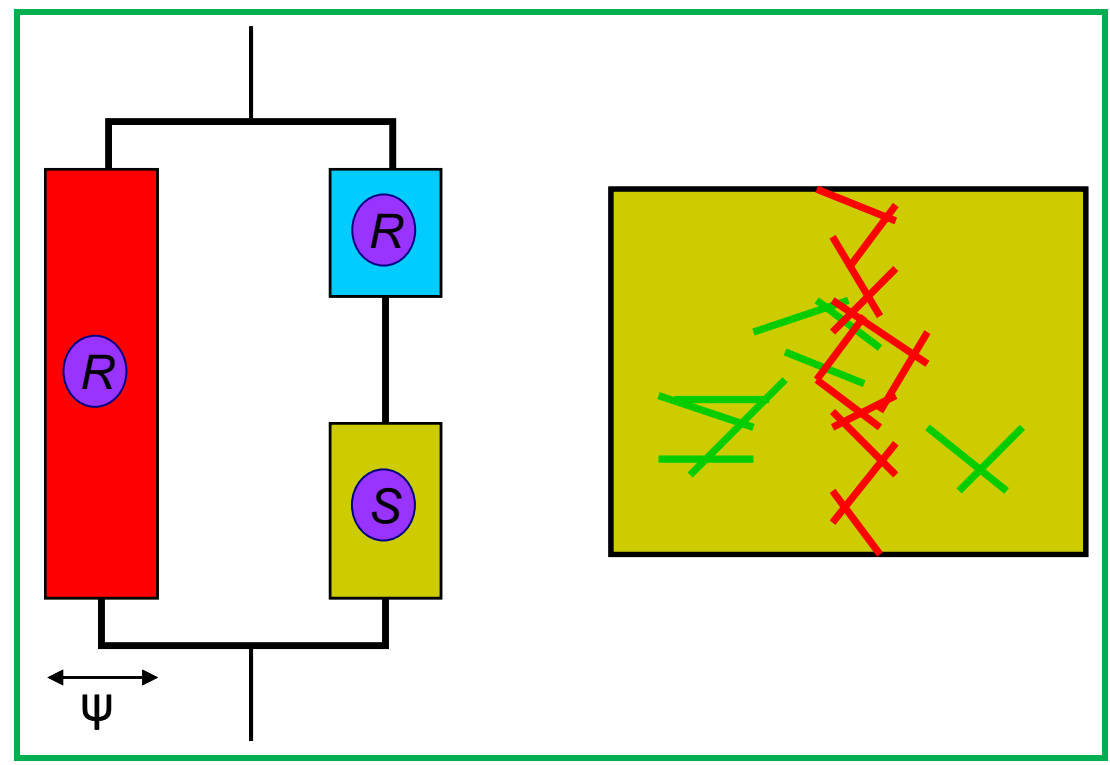

According to the model of Takayanagi et al. [131], the shear modulus of the composite can be written as:

$$
G_{c}=\frac{\left(1-2 \psi+\psi \phi_{r}\right) G_{s} G_{r}+\left(1-\phi_{r}\right) \psi G_{r}^{2}}{\left(1-\phi_{r}\right) G_{r}+\left(\phi_{r}-\psi\right) G_{s}}
$$

Where $G_{s}$ and $G_{r}$ are the shear moduli of the soft and rigid phase, respectively, $\Phi_{r}$ corresponds to the volume fraction of the rigid phase (whiskers) and $\psi$ corresponds to an adjustable parameter.

When the stiffness of the reinforcing phase is much higher than the one of the matrix material (i.e., when $G_{r} \gg G_{s}$ ), Equation (1) can be written as $\mathrm{G}=\psi G_{r}$.

In the adaptation proposed by Ouali et al. [132] to include the percolation approach, $\psi$ corresponds to the volume fraction of the percolating rigid phase, which can be estimated as:

$$
\begin{gathered}
\psi=0 \quad \Phi_{r}<\Phi_{c} \\
\psi=\phi_{r}\left(\frac{\phi_{r}-\phi_{c}}{1-\phi_{c}}\right)^{b} \quad \Phi_{r} \geq \Phi_{c}
\end{gathered}
$$

Where $b$ is the critical percolation exponent, which is equal to 0.4 for a three-dimensional system and $\Phi_{c}$ is the percolation threshold, which varies depending on the studied material and their orientation distribution. Dufresne [133] explained that the good agreement observed between experimental and predicted data by using the series-parallel model of Takayanagi modified to include the percolation approach is related to the formation of infinite aggregates of cellulose whiskers.

For rod-like nanoparticles the percolation threshold can be linked to the aspect ratio of the nanoparticles by the following equation:

$$
\phi_{c}=\frac{0.7}{L / d}
$$


In Equation (3), $L / d$ is the aspect ratio, assuming a cylindrical shape for the nanofiller, and $\Phi_{c}$ is the percolation threshold. The geometrical characteristics and the corresponding percolation threshold values for some cellulose nanocrystals are reported in Table 4.

Table 4. Geometrical characteristics (length, L, and diameter, D) and percolation threshold $\left(\Phi_{c}\right)$ of some cellulose nanocrystals.

\begin{tabular}{cccccc}
\hline Source & $\mathbf{L}(\mathbf{n m})$ & $\mathbf{D}(\mathbf{n m})$ & $\mathbf{L} / \mathbf{d}$ & $\Phi_{c}$ & Reference \\
\hline Cotton & 171.6 & 14.6 & 11.8 & 5.9 & {$[105]$} \\
Ramie & 200 & 7 & 28.6 & 2.5 & {$[36]$} \\
MCC & 200 & 5 & 40 & 1.75 & {$[104]$} \\
Sugar beet pulp & 210 & 5 & 42 & 1.7 & {$[73]$} \\
Palm tree & 260 & 6.1 & 43 & 1.6 & {$[10]$} \\
Wheat straw & 225 & 5 & 45 & 1.6 & {$[103]$} \\
Tunicin & 1,000 & 15 & 67 & 1.0 & {$[71]$} \\
\hline
\end{tabular}

The formation of a continuous cellulosic network formed when the percolation threshold is reached is probably responsible for the unusual mechanical properties of cellulose whisker reinforced nanocomposites. Moreover, Favier et al. [71] explained that the stiffness of this cellulosic network is due to strong interactions like hydrogen bonds, similarly to what is observed for a paper sheet for which the hydrogen-bonding forces hold the percolating network of fibers.

\subsubsection{Reinforcement with Cellulose Based Nanoparticles}

Cellulose whiskers with different aspect ratios isolated from different sources, like tunicin [102], linter [127], cotton [44], straw [103], and MCC [104], were evaluated as a reinforcing phase in nanocomposites using different polymer matrices such as natural rubber [10], poly(styrene-co-butyl acrylate) [102,103], PLA [127], PVA [104], and PCL [36]. In most cases, the mechanical properties could be substantially improved depending on the amount and homogeneity of cellulose filler dispersion. The strong reinforcing effect of the whiskers is generally attributed to the formation of a percolating network structure above the percolation threshold resulting from hydrogen bonding between nanoparticles [107].

Helbert et al. [103] reported that a poly(S-co-BuA) latex film containing $30 \mathrm{wt} \%$ of wheat straw cellulose whiskers presented a rubbery Young's modulus value more than 1000-times higher than that of the bulk matrix. This effect was ascribed not only to the geometry and stiffness of the whiskers, but also to the formation of a H-bonded whiskers network.

The improvement of strength and modulus of polymers, especially above the glass transition temperature $\left(\mathrm{T}_{\mathrm{g}}\right)$ of the host polymeric matrix, is widely described in the literature $[36,134]$. However, the presence of whiskers tends to decrease the elongation at break of the nanocomposites compared to the neat matrix [36,117]. For example, the addition of $10 \mathrm{wt} \%$ of cellulose palm tree whiskers in natural rubber decreased the strain at break from 575\% to $16 \%$ (as shown in Figure 9) [10]. 
Figure 9. Typical stress-strain curves obtained from tensile tests $\left(\mathrm{T}=25{ }^{\circ} \mathrm{C}\right)$ for natural rubber (NR) reinforced with cellulose date palm tree whiskers (W). The number in the codification of the sample corresponds to the whiskers content (wt\%) [10].

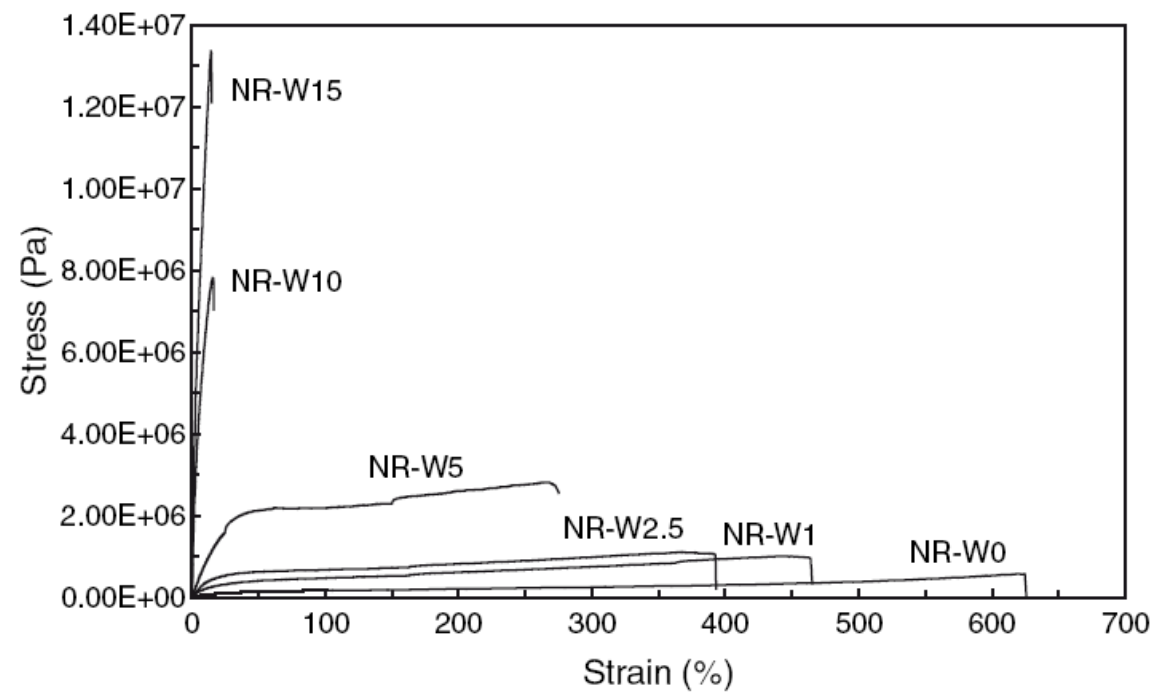

MFC isolated from kraft pulp [52,83], sulfite pulp [77], potato pulp [134], and sugar beet [135], were also studied as nanoreinforcement in different matrices such as PVA [52,77], HPC [77], potato starch plasticized with glycerol [134], and polyurethane (PU) [136,137].

Many reports have identified that the disintegration process influenced the mechanical properties of resulting nanocomposites. It can be expected that MFC with higher surface area will result in stiffer material with the same nanoparticle content due to higher contact surface facilitating the network formation. This can enhance the tensile strength when the nanocomposite film is dried. The reinforcing effect of MFC as well as for all nanocomposite material is also dependent on the interactions of the fiber with the matrix.

Zimmermann et al. [77] studied the influence of the disintegration process on the mechanical properties of PVA and HPC nanocomposites filled with cellulose fibrils isolated from a sulfite pulp. They reported that for nanocomposites reinforced with mechanically isolated fibrils, the Young's modulus increased up to a factor of 2.5 (fibril content $10 \mathrm{wt} \%$ ) for the PVA-nanocomposites, and up to a factor of 3 (fibril content $20 \mathrm{wt} \%$ ) for HPC nanocomposites compared to the neat matrix. Lu et al. [52] did not identify network structure formation for the composites of PVA with low MFC contents. The absence of network formation due to larger diameter of MFC and micro fiber aggregates can explain the lower increase $(40 \%)$ of the Young's modulus for PVA-based nanocomposites compared to PVA-based nanocomposites obtained by Zimmermann et al. [77].

The DMA experiments demonstrated that the storage modulus of PU-MFC nanocomposites was improved over the whole temperature range compared to pure PU [136,137]. Moreover, recently, Wu et al. [137] demonstrated that only a low percentage of MFC (5 wt\%) was enough to improve the modulus of the PU matrix by approximately $200 \%$ at $5{ }^{\circ} \mathrm{C}$, while at $85{ }^{\circ} \mathrm{C}$ an increase close to $500 \%$ was observed.

The use of higher quantities of MFC in filled nanocomposites was presented by Nakagaito et al. [138]. The PLA matrix was filled with up to $90 \mathrm{wt} \%$ of MFC using a similar strategy to that for impregnated 
paper. A linear increase of the Young's modulus with increasing MFC content was reported. The modulus increased from $5 \mathrm{GPa}$ for a MFC content of $10 \mathrm{wt} \%$ to almost $9 \mathrm{GPa}$ for $70 \mathrm{wt} \% \mathrm{MFC}$. This phenomenon was observed even at high temperatures. The storage modulus above the glass transition temperature increased with increasing MFC content in the composites. Moreover, for high MFC content, such as 70 and $90 \mathrm{wt} \%$, the storage modulus was sustained up to $250{ }^{\circ} \mathrm{C}$. The preparation of nanocomposites by compression molding of sheets is suggested to be easily usable by the industry.

\subsection{Thermal Properties}

The analysis of thermal properties of materials is important to determine their processing temperature range and use. It is possible to determine the main characteristics of polymeric systems such as glass-rubber transition temperature $\left(\mathrm{T}_{\mathrm{g}}\right)$, melting point $\left(\mathrm{T}_{\mathrm{m}}\right)$ and thermal stability through differential scanning calorimetry (DSC) experiments. Dynamical mechanical analyses can also be used to evaluate the $\mathrm{T}_{\mathrm{g}}$ of polymers.

In DSC experiments, the $\mathrm{T}_{\mathrm{g}}$ is generally determined as the inflection point of the specific heat increment at the glass-rubber transition. However, a relaxation process is evidenced in the $\mathrm{T}_{\mathrm{g}}$ temperature range, by DMA analyses.

Several authors did not observed important changes in the $\mathrm{T}_{\mathrm{g}}$ of nanocomposites reinforced with cellulose nanofillers. This result was surprising due to the high specific area of such nanofillers, e.g., around $170 \mathrm{~m}^{2} \mathrm{~g}^{-1}$ for tunicin whiskers [139]. Studies of PEO reinforced with tunicin whiskers did not show any significant influence of the whisker content on the $T_{g}$ of the materials [140]. Similar observation was reported by Grunert et al. [43] in their work with cellulose acetate butyrate (CAB) reinforced with bacterial cellulose nanocrystals. More recently, Lu et al. [52] evaluated the thermal properties of polyvinyl alcohol (PVA) reinforced with microfibrillated cellulose. According to these authors, no change of $\mathrm{T}_{\mathrm{g}}$ was detected.

Anglès et al. [139] reported a peculiar effect on the $\mathrm{T}_{\mathrm{g}}$ of the starch-rich fraction of glycerol plasticized starch based nanocomposites reinforced with tunicin whiskers. It was determined that the $\mathrm{T}_{\mathrm{g}}$ of nanocomposites depended on moisture conditions. For low loading levels (up to $3.2 \mathrm{wt} \%$ ), a classical plasticization effect of water was reported. However, an anti-plasticization phenomenon was observed for higher whisker content ( $6.2 \mathrm{wt} \%$ and up). These observations were discussed according to (i) the possible interactions between hydroxyl groups on the cellulosic surface and starch, (ii) the selective partitioning of glycerol and water in the bulk starch matrix or at whiskers surface, and (iii) the restriction of amorphous starch chain mobility in the vicinity of the starch crystallite coated filler surface.

The plasticizing effect of water molecules is considered to be responsible for the decrease of $\mathrm{T}_{\mathrm{g}}$ values in PVAc and PVA-based nanocomposites reinforced with sisal [72] and cotton [105] whiskers. Regardless of the composition, a decrease of $\mathrm{T}_{\mathrm{g}}$ was observed as the humidity content increased. However, in moist atmosphere, the $\mathrm{T}_{\mathrm{g}}$ of PVA-based nanocomposites significantly increased when cotton whiskers were added [105]. For glycerol plasticized starch nanocomposite reinforced with cellulose crystallites prepared from cottonseed linter [141], an increase of $\mathrm{Tg}$ with filler content was reported and attributed to cellulose/starch interactions. 
For tunicin whiskers/sorbitol plasticized starch nanocomposite [142], $\mathrm{T}_{\mathrm{g}} \mathrm{s}$ were found to increase slightly up to about $15 \mathrm{wt} \%$ whiskers and to decrease for higher whiskers loading. Crystallization of amylopectin chains upon whiskers addition and migration of sorbitol molecules to the amorphous domains were proposed to explain the observed modifications. The $T_{g}$ of electrospun PS fiber with added cellulose whiskers (and surfactant) [38] tends to decrease with the whisker content. The authors attributed the reduction of $\mathrm{T}_{\mathrm{g}}$ to the plasticizing effect of the surfactant.

$\mathrm{T}_{\mathrm{m}}$ values are reported to be nearly independent of the filler content in PCL/chitin whiskers nanocomposites [143] as well as in POE filled with tunicin whiskers [140]. The same observation was reported for PVA reinforced with microfibrillated cellulose [52] and CAB reinforced with unmodified bacterial cellulose nanocrystals [43]. However, when bacterial cellulose nanocrystals were modified with silane groups, $\mathrm{T}_{\mathrm{m}}$ values were founded to increase with increasing filler content. According to the authors, this difference was due to stronger interactions between silylated whiskers and PVA matrix.

The heat of fusion $\left(\Delta H_{m}\right)$ allows the determination of the degree of crystallinity $\left(\chi_{c}\right)$ of the composites. $\chi_{\mathrm{c}}$ values can be obtained by dividing the heat of fusion of the material by that of the $100 \%$ crystalline matrix. It is necessary to normalize $\Delta H_{m}$ values to account for the effective amount of matrix material if any discussion about filler content is done. A slight increase in crystallinity of PVA-MFC nanocomposites [52] was reported upon addition of a low amount of MFC ( 1 to $5 \mathrm{wt} \%$ ) to PVA matrix. This phenomenon was ascribed to the anchoring effect of the cellulosic filler, possibly acting as nucleating agent. For MFC content above 5 wt\% (e.g., 10 and $15 \mathrm{wt} \%$ ), a decrease of the crystallinity of PVA nanocomposites compared to the matrix was observed. Studies of the melting and crystallization behavior of PCL chains grafted onto the surface of MFC and ungrafted PCL at different cooling rates have shown that the degree of crystallinity $\left(\chi_{c}\right)$ for grafted PCL is lower than for ungrafted PCL. In this study, MFC has been grafted with PCL chains of different theoretical lengths. In general, it was determined that higher molecular weight of ungrafted PCL results in lower $\chi_{c}$.

The higher crystallinity of PLA-MFC [53] nanocomposites compared to neat PLA showed that MFC accelerated the crystallization of PLA. In this study, MFC was also supposed to act as a nucleating agent accelerating the crystallization of PLA. The degree of crystallinity $\left(\chi_{c}\right)$ for PEO nanocomposites reinforced with tunicin whiskers [140] was found to be quite constant up to $10 \mathrm{wt} \%$ of whisker content, but to decrease for higher whisker loading (e.g., 15 and $30 \mathrm{wt} \%$ ). The DSC measurements of PEO and PEO-nanocomposites are shown in Figure 10. This result was attributed to a steric phenomenon of PEO spherulites growing in the presence of the cellulose network. It seems that the nucleating effect of cellulosic nanocrystals is mainly governed by surface chemical considerations [140].

The degree of crystallinity of PCL decreased with the addition of Riftia tubes chitin whiskers [143]. It was suggested that during crystallization, the rod-like nanoparticles are most probably first ejected and then occluded in intercrystalline domains, hindering the crystallization of the polymer. DMA analyses have shown that $\tan \delta$ peak of PVA slightly shifts to lower temperatures when the matrix is filled with up to $15 \mathrm{wt} \%$ of MFC [52]. A decrease in the intensity of the tan $\delta$ peak of composites compared to the pure matrix was also observed and it was ascribed to a reduced fraction of polymer matrix in the composites. 
For CAB nanocomposites [144] reinforced with $5 \mathrm{wt} \%$ cellulose whiskers from MCC, it was reported that the $\tan \delta$ peak of the matrix was affected by the presence of the cellulosic filler. A slight decrease of $\tan \delta$ from 158 to $152{ }^{\circ} \mathrm{C}$ was reported. In a different way, for PLA nanocomposites [37], cellulose whiskers contributed to increase the tan $\delta$ peak by $5{ }^{\circ} \mathrm{C}$, indicating minor hindering of segmental motions of PLA matrix. The authors observed a larger shift in $\tan \delta$ peak when whiskers were solvent exchanged to butanol before freeze-drying these fillers. The presence of surfactant $(20 \mathrm{wt} \%)$ in the nanocomposite was also evaluated. The higher shift and increased magnitude of the $\tan \delta$ peak in the experiments was attributed to the presence of the surfactant. The surfactant was able to hinder the segmental movements of PLA chains. Higher interaction level between cellulosic nanoparticles and PLA chains resulted in an increase of the temperature position of the $\tan \delta$ peak. None or little interaction between whiskers and surfactant was reported. The authors have suggested that an interaction between whiskers and surfactant would have shifted the $\tan \delta$ peak to higher temperatures, which was not observed.

Figure 10. DSC thermograms showing the non-isothermal crystallization at $10{ }^{\circ} \mathrm{C} \mathrm{min}-1$ for PEO based composites filled with $0(\bigcirc), 10(\square)$, and $30 \mathrm{wt} \%(\diamond)$ of tunicin whiskers [140].

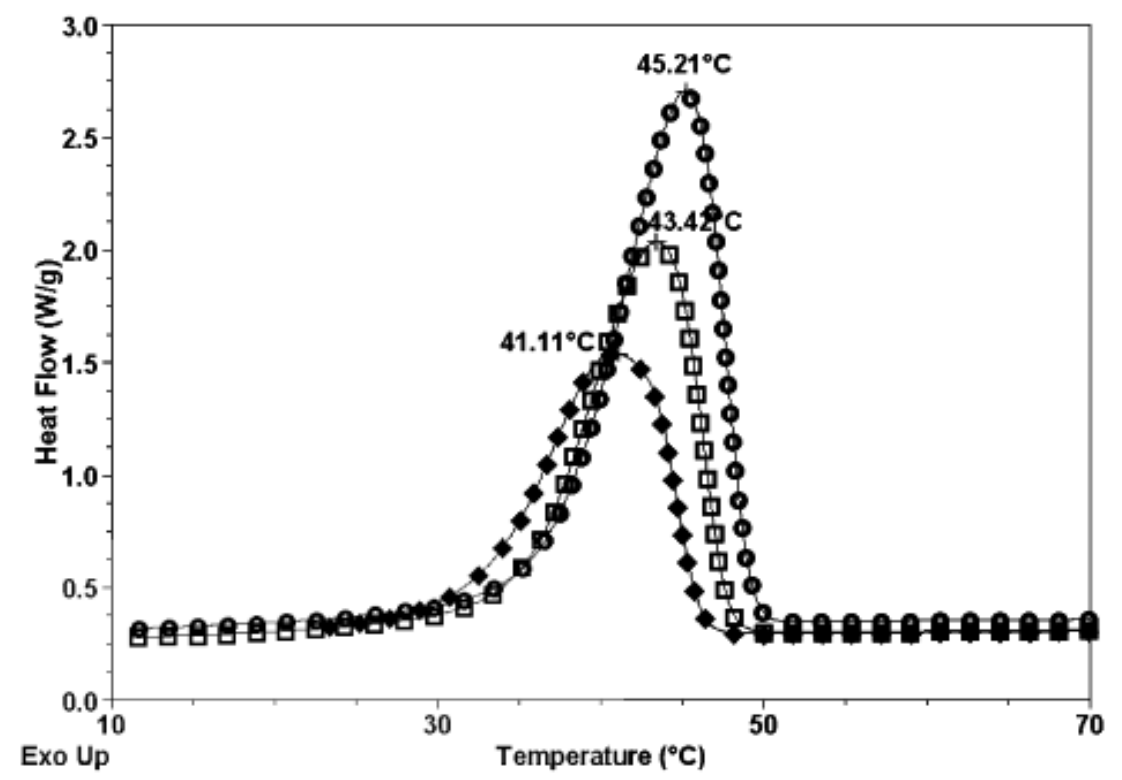

\subsection{Barrier Properties}

The great interest in nanoparticles for composites applications originates from outstanding mechanical properties. Improved properties can often be reached for low filler volume fractions without affecting other properties such as impact resistance of plastic deformation capability [13]. However, there is an increasing interest in the barrier properties due to increased tortuosity provided by nanoparticles. Indeed, most materials used for food packaging are practically non-degradable petrochemical based polymers, representing a serious environmental problem. The main reason for their use is due to the ease of processability, and their low cost and excellent barrier properties [145]. However, there is an increasing interest in the development of a new class of biodegradable materials with good barrier properties. Bionanocomposites belong to this category. Besides reinforcing effect, 
nanoparticles can be used to improve not only barrier properties but also other functions like active or "smart" properties of packaging, i.e., antimicrobial activity, enzyme immobilization and biosensing.

A recent study has demonstrated that the presence of MFC strongly modifies the diffusion properties of starch [146]. This study demonstrated that for glycerol plasticized nanocomposites filled with $70 \mathrm{wt} \%$ of MFC, the moisture uptake of the composite was reduced to half value of the pure plasticized starch film. However, the average and initial diffusion coefficients decreased with increasing MFC content and increased with glycerol content. Possible porosity in the nanocomposite films due to the presence of MFC was responsible for the reduction of the efficiency of cellulose nanofibers in the composite's moisture diffusivity. Finally, the reduction of moisture diffusivity in nanocomposites (cellulose nanofiber/plasticized amylopectin) may be due to three main reasons: (i) cellulose characteristics and geometrical impedance, (ii) swelling constraints due to high-modulus/hydrogen bonded MFC network, and (iii) strong molecular interactions between MFC and with the amylopectin matrix. In 2009, the barrier properties of pure MFC films were studied by Syverud et al. [145]. In this study, the gas permeability (oxygen) of the samples was measured and it was shown that the oxygen transmission rate (OTR) was quite low. For pure MFC films, the ORT values were 17.0 and $17.8 \mathrm{~mL} \mathrm{~m}^{-2} \mathrm{day}^{-1}$. These values are in the range of the recommended ORT for modified atmosphere packaging (below 10-20 $\mathrm{mL} \mathrm{m}^{-2}$ day $^{-1}$ ). The good barrier properties of pure MFC films were ascribed to the low permeability of cellulose generally enhanced with the crystalline structure of the fibrils. Recently, similar coating of MFC (from TEMPO treatment) on PLA films allowed decreasing the OTR from 746 to $1 \mathrm{~mL} \mathrm{~m}^{-2}$ day $^{-1} \mathrm{~Pa}^{-1}$, respectively, for pure PLA film and PLA coated with MFC [147].

The permeability to oxygen of PLA reinforced with microcrystalline cellulose (MCC) was studied, in 2006 by Peterson et al. [148]. The authors compared the barrier properties of pure PLA with those obtained for composites reinforced with MCC and bentonite. Bentonite was found to be more efficient than MCC due to its exfoliated structure and largest sheets compared to MCC, which is not exfoliated. Despite the increasing number of papers reporting the use of starch nanocrystals in polymer nanocomposites to improve the barrier properties [66,149], limited use of cellulose nanocrystals for this purpose has been reported. This may be due to (i) the rod-like shape of nanocrystals that can be less effective than platelet-like, or (ii) nanofiber organization.

A new application of cellulose nanofillers is barrier membranes. Many membranes are designed to prevent the permeation of hydrophilic substances, such as water or hydrophobic substances such as many toxic chemicals. Here, the most effective filler material is likely to be hydrophilic such as cellulose whiskers and MFC. The use of TEMPO-oxidized cellulose whiskers obtained from Whatman paper was investigated as barrier membranes in a poly(vinyl alcohol) (PVA) matrix [41]. The incorporation of cellulose nanocrystals reduces the water vapor transmission rate (WVTR) of the membranes. However, the results were more interesting when nanocomposites were prepared by mixing PVA matrix with low quantities (10 or $20 \mathrm{wt} \%$ ) of poly (acrylic acid) (PAA) and whiskers. These results can be ascribed to the crosslinking with PAA that reduces the number of hydroxyl groups in the composites and thus the hydrophilicity. The incorporation of cellulose nanocrystals into the nanocomposite provides a physical barrier through the creation of a tortuous path for the permeating moisture. Consequently, the addition of $10 \mathrm{wt} \%$ of cellulose nanocrystals reduced the WVTR of the matrix more than addition of PAA. The combination of $10 \mathrm{wt} \%$ whiskers and $10 \mathrm{wt} \%$ PAA gave the 
best performance. With respect to the chemical vapor transmission rate (CVPR), nanocomposites containing $10 \mathrm{wt} \%$ cellulose whiskers and $10 \mathrm{wt} \%$ PAA exhibit the same synergetic effects with time lag increasing and flux decreasing. Overall, membrane barrier properties were improved by the addition of cellulosic crystals in combination with PAA. In another study, the effect of soft wood cellulose whiskers on water vapor barrier properties of xylan/sorbitol films has been reported [150]. The nanocomposites were prepared with different amounts of whiskers (0 to $50 \mathrm{wt} \%$ ). The incorporation of sulfonated cellulose whiskers at low content reduced the water vapor transmission rate (WVTR) of xylan/sorbitol films. Specifically, $10 \mathrm{wt} \%$ sulfonated whiskers nanocomposites decreased the WVTR from $304 \mathrm{~g} \mathrm{~h}^{-1} \mathrm{~m}^{-2}$ (unfilled film) to $174 \mathrm{~g} \mathrm{~h}^{-1} \mathrm{~m}^{-2}$. The authors believed that the high degree of crystallinity of whiskers and its rigid hydrogen-bonded network governed by a percolation mechanism are responsible for the improvement of barrier properties of the films, decreasing then the WVTR of the final nanocomposite.

\section{Conclusions}

The present review reports the use of cellulose nanoparticles, whiskers and MFC, as reinforcements in polymer matrices. This review is aimed at providing knowledge to stimulate further research in this area. It has been shown that during the last 15 years an increasing number of researches in the area of cellulose nanocomposites have been developed. The possibility of surface chemical modification and nanosized dimensions of cellulose nanoparticles have been extensively used in a wide variety of application, e.g., packaging, adhesives and electronic display materials. The present contribution summarizes some selected works in the field of cellulose nanofillers extracted from different sources and by different methods. The influence of the source of cellulose on the mechanical properties of bionanocomposites was reported. Moreover, it was found that different terminologies are used to classify cellulose nanoparticles, leading to some misunderstanding and ambiguities around the subject, rather than unifying and clarifying the comprehension. Rod-like nanoparticles are basically prepared by chemical methods e.g., acid hydrolysis of biomass with sulfuric acid and hydrochloric acid. On the other hand, MFC is prepared by chemical methods, mechanical shearing or by a combination of enzymatic hydrolysis and mechanical shearing. These different preparation methods lead to different final products, which result in nanocomposites with different mechanical, thermal, and barrier properties. Despite the constant growing scientific production in the field of nanocomposites, the practical transition from laboratory scale to industrial is not so simple and requires the development of technology in the field of chemical engineering to reduce the production costs of such nanoparticles.

\section{Acknowledgments}

The authors gratefully acknowledge AlBan Program for the financial support ( $\mathrm{PhD}$ fellowship of G. S.).

\section{References}

1. FAO. Available online: www.naturalfibres2009.org (accessed on 8 December 2010). 
2. Satyanarayana, K.G.; Guilmaraes, J.L.; Wypych, F. Studies on lignocellulosic fibers of Brazil. Part I: Source, production, morphology, properties and applications. Compos. A-Appl. Sci. Manufact. 2007, 38, 1694-1709.

3. FAOSTAT. Available online: www.faostat.fao.org (accessed on 8 December 2010).

4. Moir, B.; Plastina, A. 2009 international year of natural fibers. J. Int. Forum Cotton Promotion 2010, 26, Available online: http://www.cottonpromotion.org/features/international_year_of_ natural_fibers/ (accessed on 8 December 2010).

5. Bledzki, A.K.; Gassan, J. Composites reinforced with cellulose based fibres. Prog. Polym. Sci. 1999, 24, 221-274.

6. Satyanarayana, K.G.; Sukumaran, K.; Mukherjee, P.S.; Pavithran, C.; Pillai, S.G.K. Natural fibre-polymer composites. Cem. Concr. Compos. 1990, 12, 117-136.

7. Rong, M.Z.; Zhang, M.Q.; Liu, Y.; Yang, G.C.; Zeng, H.M. The effect of fiber treatment on the mechanical properties of unidirectional sisal-reinforced epoxy composites. Compos. Sci. Technol. 2001, 61, 1437-1447.

8. Dufresne, A. Cellulose-based composites and nanocomposites. In Monomers, Polymers and Composites from Renewable Resources, 1st ed.; Gandini, A., Belgacem, M.N., Eds.; Elsevier: Oxford, UK, 2008; pp. 401-418.

9. Satyanarayana, K.G.; Wypych, F. Characterization of natural fibers. In Handbook of Engineering Biopolymers: Homopolymers, Blends and Composites; Fakirov, S., Bhattacharyya, D., Eds.; Carl Hanser Verlag: Munchen, Germany, 2007; pp. 4-47.

10. Bendahou, A.; Habibi, Y.; Kaddami, H.; Dufresne, A. Physico-chemical characterization of palm from Phoenix Dactylifera-L, preparation of cellulose whiskers and natural rubber-based nanocomposites. J. Biobased Mat. Bioenerg. 2009, 3, 81-90.

11. Razera, I.A.T.; Frollini, E. Composites based on jute fibers and phenolic matrices: Properties of fibers and composites. J. Appl. Polym. Sci. 2004, 91, 1077-1085.

12. Rowell, R.M.; Han, J.S.; Rowell, J.S. Characterization and factors effecting fiber properties. In Natural Polymers and Agrofibers Composites; Frollini, E., Leão, A.L., Mattoso, L.H.C., Eds.; Embrapa Instrumentação Agropecuária: Sao Carlos, Brazil, 2000.

13. Dufresne, A. Polymer nanocomposites from Biological Sources. In Encyclopedia of Nanoscience and Nanotechnology, 2nd ed.; Nalwa, H.S., Ed.; American Scientific Publisher: Valencia, CA, USA; in press.

14. Heux, L.; Dinand, E.; Vignon, M.R. Structural aspects in ultrathin cellulose microfibrils followed by ${ }^{13}$ C CP-MAS NMR. Carbohydr. Polym. 1999, 40, 115-124.

15. Brännvall, E. Aspect on Strength Delivery and Higher Utilisation of Strength Potential of Soft Wood Kraft Pupl Fibres. Ph.D. Thesis, KTH, Royal Institute of Technology: Stockholm, Sweden, 2007.

16. John, M.J.; Thomas, S. Biofibres and biocomposites. Carbohydr. Polym. 2008, 71, 343-364.

17. Sjöström, E. Wood Chemistry Fundamentals and Applications; Academic Press: New York, NY, USA, 1981.

18. Daniel, J.R. Cellulose structure and properties. In Encyclopedia of Polymer Science and Engineering; Kroschwitz, J.I., Ed.; Wiley-Interscience Publication John Wiley \& Sons: New York, NY, USA, 1985; Volume 3, pp. 86-123. 
19. Andresen, M.; Johansson, L.S.; Tanem, B.S.; Stenius, P. Properties and characterization of hydrophobized microfibrillated cellulose. Cellulose 2006, 13, 665-677.

20. Dufresne, A.; Cavaille, J.Y.; Vignon, M.R. Mechanical behavior of sheets prepared from sugar beet cellulose microfibrils. J. Appl. Polym. Sci. 1997, 64, 1185-1194.

21. Stenstad, P.; Andresen, M.; Tanem, B.S.; Stenius, P. Chemical surface modifications of microfibrillated cellulose. Cellulose 2008, 15, 35-45.

22. Azizi Samir, M.A.S.; Alloin, F.; Dufresne, A. Review of recent research into cellulosic whiskers, their properties and their application in nanocomposite field. Biomacromolecules 2005, 6, 612-626.

23. Lu, J.; Askeland, P.; Drzal, L.T. Surface modification of microfibrillated cellulose for epoxy composite applications. Polymer 2008, 49, 1285-1296.

24. Montanari, S.; Roumani, M.; Heux, L.; Vignon, M.R. Topochemistry of carboxylated cellulose nanocrystals resulting from TEMPO-mediated oxidation. Macromolecules 2005, 38, 1665-1671.

25. Dinand, E.; Vignon, M.; Chanzy, H.; Heux, L. Mercerization of primary wall cellulose and its implication for the conversion of cellulose I $\rightarrow$ cellulose II. Cellulose 2002, 9, 7-18.

26. Sugiyama, J.; Persson, J.; Chanzi, H. Combined infrared and electron diffraction study of polymorphism of native cellulose. Macromolecules 1991, 24, 2461-2466.

27. French, A.D.; Bertoniere, N.R.; Brown, R.M.; Chanzy, H.; Gray, D.; Hattori, K.; Glasser, W. Cellulose. In Encyclopedia of Polymler Science and Technology; Kroschwitz, J.I., Ed.; Wiley Interscience Publication John Wiley \& Sons: New Jersey, NJ, USA, 2003; Volume 5, pp. 473-507.

28. Saxena, I.M.; Brown, R.M.J. Cellulose Biosynthesis: Current views and envolving Concepts. Ann. Bot. 2005, 96, 9-21.

29. U.S. Department of Energy, Office of Science. Genomics: GTL Roadmap; Available online: http://genomicsgtl.energy.gov/roadmap/ (accessed on 8 December 2010).

30. Atalla, R.H.; VanderHart, L.D. Native cellulose: A composite of two distinct crystalline forms. Science 1984, 223, 283-285.

31. Sugiyama, J.; Okano, T.; Yamamoto, H.; Horii, F. Transformation of Valonia cellulose crystals by an alkaline hydrothermal treatment. Macromolecules 1990, 23, 3196-3198.

32. Sugiyama, J.; Vuong, R.; Chanzi, H. Electron diffraction study on the two crystalline phases occurring in native cellulose from an algal cell wall. Macromolecules 1991, 24, 4168-4175.

33. de Souza Lima, M.M.; Borsali, R. Rodlike cellulose microcrystals: Structure, properties and applications. Macromol. Rapid Commun. 2004, 25, 771-787.

34. Nishiyama, Y.; Sugiyama, J.; Chanzy, H.; Langan, P. Crystal structure and hydrogen bonding system in cellulose 1(alpha), from synchrotron X-ray and neutron fiber diffraction. J. Am. Chem. Soc. 2003, 125, 14300-14306.

35. Lu, J.; Askeland, P.; Drzal, L.T. Surface modification of microfibrillated cellulose for epoxy composite applications. Polymer 2008, 49, 1285-1298.

36. Habibi, Y.; Goffin, A.L.; Schiltz, N.; Duquesne, E.; Dubois, P.; Dufresne, A. Bionanocomposites based on poly(epsilon-caprolactone)-grafted cellulose nanocrystals by ring-opening polymerization. J. Mater. Chem. 2008, 18, 5002-5010. 
37. Petersson, L.; Kvien, I.; Oksman, K. Structure and thermal properties of poly(lactic acid)/cellulose whiskers nanocomposites materials. Compos. Sci. Technol. 2007, 67, 2535-2544.

38. Rojas, O.J.; Montero, G.A.; Habibi, Y. Electronspun nancomposites from polystyrene loaded with cellulose nanowhiskers. Appl. Polym. Sci. 2009, 113, 927-935.

39. Pandey, J.K.; Kim, S.C.; Chu, C.S.; Lee, C.S.; Jang, D.J.; Ahn, S.H. Evaluation of morphological architecture of cellulose chains in grass during conversion from macro to nano dimensions. e-Polymer 2009, 102, 1-15.

40. Oksman, K.; Mathew, A.P.; Bondeson, D.; Kvien, I. Manufacturing process of cellulose whiskers/polylactic acid nanocomposites. Compos. Sci. Technol. 2006, 66, 2776-2784.

41. Paralikar, S.A.; Simonsen, J.; Lombardi, J. Poly(vinyl alcohol)/cellulose nanocrystals barrier membranes. J. Membr. Sci. 2008, 320, 248-258.

42. Mangalam, A.P.; Simonsen, J.; Benight, A. Cellulose/DNA hybrid nanomaterials. Biomacromolecules 2009, 10, 497-504.

43. Grunert, M.; Winter, W.T. Nanocomposites of cellulose acetate butyrate reinforced with cellulose nanocrystals. J. Polym. Envir. 2002, 10, 27-30.

44. Morandi, G.; Heath, L.; Thielemans, W. Cellulose nanocrystals grafted with polystyrene chains through surface-initiated atom transfer radical polymerization (SI-ATRP). Langmuir 2009, 25, 8280-8286.

45. Bondeson, D.; Mathew, A.; Oksman, K. Optimization of the isolation of nanocrystals from microcrystalline cellulose by acid hydrolysis. Cellulose 2006, 13, 171-180.

46. Filson, P.B.; Dawson-Andoh, B.E. Sono-chemical preparation of cellulose nanocrystals from lignocellulose derived materials. Biores. Technol. 2009, 100, 2259-2264.

47. Braun, B.; Dorgan, J.R.; Chandler, J.P. Cellulosic nanowhiskers. Theory and application of light scattering from polydisperse spheroids in the Rayleigh-Gans-Debye regime. Biomacromoleucules 2008, 9, 1255-1263.

48. Dufresne, A.; Cavaille, J.Y.; Helbert, W. Thermoplastic nanocomposites filled with wheat straw cellulose whiskers. Part II. Effect of processing and modeling. Polym. Compos. 1997, 18, 198-210.

49. Alemdar, A.; Sain, M. Biocomposites from wheat straw nanofibers: Morphology, thermal and mechanical properties. Comp. Sci. Technol. 2008, 68, 557-565.

50. Bai, W.; Holbery, J.; Li, K. A techinique for production of nanocrystalline cellulose with a narrow size distribution. Cellulose 2009, 16, 455-465.

51. Andresen, M.; Stenius, P. Water-in-oil emulsions stabilized by hydrophobized microfibrillated cellulose. J. Disp. Sci. Technol. 2007, 28, 837-844.

52. Lu, J.; Wang, T.; Drzal, L.T. Preparation and properties of microfibrillated cellulose polyvinyl alcohol composite materials. Compos. A Appl. Sci. Manuf. 2008, 39, 738-746.

53. Suryanegara, L.; Nakagaito, A.N.; Yano, H. The effect of crystallization of PLA on the thermal and mechanical properties of microfibrillated cellulose-reinforced PLA composites. Comp. Sci. Technol. 2009, 69, 1187-1192.

54. Mörseburg, K.; Chinga-Carrasco, G. Assessing the combined benefits of clay and nanofibrillated cellulose in layered TMP-based sheets. Cellulose 2009, 16, 795-806. 
55. Chinga-Carrasco, G.; Syverud, K. Computer-assisted quantification of the multi-scale structure of films made of nanofibrillated cellulose. J. Nanopart. Res. 2010, 12, 841-851.

56. Battista, O.A.; Hill, D.; Smith, P.A. Microcrystalline cellulose. Ind. Eng. Chem. 1962, 20, 54-59.

57. Dong, X.M.; Kimura, T.; Revol, J.F.; Gray, D.G. Effects of ionic strength on the isotropic-chiral nematic phase transition of suspensions of cellulose crystallites. Langmuir 1996, 12, 2076-2082.

58. Moran, J.I.; Alvarez, V.A.; Cyras, V.P.; Vazquez, A. Extraction of cellulose and preparation of nanocellulose from sisal fibers. Cellulose 2008, 15, 149-159.

59. Araki, J.; Wada, M.; Kuga, S. Steric stabilization of a cellulose microcrystal suspension by poly(ethylene glycol) grafting. Langmuir 2001, 17, 21-27.

60. Wang, B.; Mohini, S. Isolation of nanofibers from soybean source and their reinforcing capability on synthetic polymers. Comp. Sci. Technol. 2007, 67, 2521-2527.

61. Habibi, Y.; Lucia, L.A.; Rojas, O.J. Cellulose nanocrystals: Chemistry, self-assembly, and applications. Chem. Rev. 2010, 110, 3479-3500.

62. Thielemans, W.; Warbey, C.R.; Walsh, D.A. Permselective nanostructured membranes based on cellulose nanowhiskers. Green Chem. 2009, 11, 531-537.

63. Beck-Candanedo, S.; Roman, M.; Gray, D. Effect of conditions on the properties behavior of wood cellulose nanocrystals suspensions. Biomacromolecules 2005, 6, 1048-1054.

64. Dong, X.M.; Revol, J.F.; Gray, D. Effect of microcrystallite preparation conditions on the formation of colloid crystals of cellulose. Cellulose 1998, 5, 19-32.

65. Araki, J.; Wada, M.; Kuga, S.; Okano, T. Low properties of microcrystalline cellulose suspension prepared by acid treatement of native cellulose. Colloids Surf. A 1998, 142, 75-82.

66. Angellier, H.; Putaux, J.L.; Molina-Boisseau, S.; Dupeyre, D.; Dufresne, A. Starch nanocrystal fillers in a acrylic polymer matrix. Macromol. Symp. 2005, 221, 95-104.

67. Hirai, A.; Inui, O.; Horii, F.; Tsuji, M. Phase separation behavior in aqueous suspensions of bacterial cellulose nanocrystals prepared by sulfuric acid treatment. Langmuir 2009, 25, 497-502.

68. Sugiyama, J.; Chanzi, H.; Revol, J.F. On the polarity of cellulose in the cell wall of Valonia. Planta 1994, 193, 260-265.

69. Cao, X.; Chen, Y.; Chang, P.R.; Stumborg, M.; Huneault, M.A. Green Composites Reinforced with Hemp Nanocrystals in Plasticized Starch. J. Appl. Polym. Sci. 2008, 109, 3804-3810.

70. Bonini, C.; Heux, L.; Cavaille, J.Y.; Lindner, P.; Dewhurst, C.; Terech, P. Rodlike cellulose whiskers coated with surfactant: A small-angle neutron scattering characterization. Langmuir 2002, 18, 3311-3314.

71. Favier, V.; Chanzy, H.; Cavaille, J.Y. Polymer nanocomposites reinforced by cellulose whiskers. Macromolecules 1995, 28, 6365-6367.

72. Garcia de Rodriguez, N.L.; Thielemans, W.; Dufresne, A. Sisal cellulose whiskers reinforced polyvinyl acetate nanocomposites. Cellulose 2006, 13, 261-270.

73. Azizi Samir, M.A.S.; Alloin, F.; Paillet, M.; Dufresne, A. Tangling effect in fibrillated cellulose reinforced nanocomposites. Macromolecules 2004, 37, 4313-4316.

74. Favier, V. Etude de Nouveaux Matériaux Composites Obtenus à Partir de Latex Filmogènes et de Whiskers de Cellulose: Effect de Percolation Mechanique. Ph.D. Thesis, Joseph Fourier University: Grenoble, France, 1995. 
75. Kvien, I.; Tanem, B.S.; Oksman, K. Characterization of cellulose whiskers and their nanocomposites by atomic force and electron microscopy. Biomacromolecules 2005, 6, 3160-3165.

76. Sakurada, I.; Nukushina, Y.I.T. Experimental determination of the elastic modulus of crystalline regions in oriented polymers. J. Polym. Sci. 1962, 57, 651-659.

77. Zimmermann, T.; Pohler, E.; Geiger, T. Cellulose fibrils for polymer reinforcement. Adv. Eng. Mat. 2004, 6, 754-761.

78. Herrick, F.W.; Casebier, R.L.; Hamilton, J.K.; Sandberg, K.R. Microfibrillated cellulose: Morphology and accessibility. J. Appl. Polym. Sci. Appl. Polym. Symp. 1983, 37, 797-813.

79. Turbak, A.F.; Snyder, F.W.; Sandberg, K.R. Microfibrillated cellulose, a new cellulose product: Properties, uses, and commercial potential. J. Appl. Polym. Sci. Appl. Polym. Symp. 1983, 37, 815-827.

80. Nakagaito, A.N.; Yano, H. Novel high-strength biocomposites based on microfibrillated cellulose having nano-order-unit web-like network structure. Appl. Phys. A-Mat. Sci. Process. 2005, 80, 155-159.

81. Iwamoto, S.; Kai, W.; Isogai, A.; Iwata, T. Elastic modulus of single cellulose microfibrils from tunicate measured by atomic force microscopy. Biomacromolecules 2009, 10, 2571-2576.

82. Henriksson, M.; Henriksson, G.; Berglund, L.A.; Lindstrom, T. An environmentally friendly method for enzyme-assisted preparation of microfibrillated cellulose (MFC) nanofibers. Europ. Polym. J. 2007, 43, 3434-3441.

83. Nakagaito, A.N.; Yano, H. The effect of morphological changes from pulp fiber towards nano-scale fibrillated cellulose on the mechanical properties of high-strength plant fiber based composites. Appl. Phys. A-Mat. Sci. Process. 2004, 78, 547-552.

84. Ankerfors, M.P.; Kosonen, H.; Nyknen, A.; Ahola, S.; Sterberg, M.; Roukolainen, J.; Laine, J.; Larsson, P.T.; Ikkala, O.; Lindstrm, T. Enzymatic hydrolisis combined with mechanical shearing and high-pressure homogenization for nanoscale cellulose fibrils and strong gels. Biomacromolecules 2007, 8, 1934-1941.

85. Saito, T.; Nishiyama, Y.; Putaux, J.L.; Vignon, M.; Isogai, A. Homogeneous suspensions of individualized microfibrils from TEMPO-catalyzed oxidation of native cellulose. Biomacromolecules 2006, 7, 1687-1691.

86. Saito, T.; Kimura, S.; Nishiyama, Y.; Isogai, A. Cellulose nanofibers prepared by TEMPO-mediated oxidation of native cellulose. Biomacromolecules 2007, 8, 2485-2491.

87. Kamel, S. Nanotechnology and its application in lignocellulosics composites, a mini review. Exp. Polym. Lett. 2007, 1, 546-575.

88. Khademhosseini, A.; Langer, R. Nanobiotechnology-Drug delivery and tissue engineering. Chem. Engin. Progress 2006, 102, 38-42.

89. Dalmas, F.; Cavaille, J.Y.; Gauthier, C.; Chazeau, L.; Dendievel, R. Viscoelastic behavior and electrical properties of flexible nanofiber filled polymer nanocomposites. Influence of processing conditions. Comp. Sci. Technol. 2007, 67, 829-839.

90. Esteves, A.C.C.; Barros-Timmons, A.; Trindade, T. Polymer based nanocomposites: Synthetic strategies for hybrid materials. Quim. Nova 2004, 27, 798-806. 
91. Azeredo, M.C. Nanocomposites for food packaging applications. Food Res. Int. 2009, 42, 1240-1253.

92. Schadler, L.S.; Brinson, L.C.; Sawyer, W.G. Polylmer nanocomposites: A small part of the story. Nanocompos. Mat. 2007, 59, 53-60.

93. Kovacs, T.; Naish, V.; O’Connor, B.; Blaise, C.; Gagné, F.; Hall, L.; Trudeau, V.; Martel, P. An ecotoxicological characterization of nanocrystalline cellulose (NCC). Nanotoxicology 2010, 4, 255-270.

94. Mohanty, A.K.; Misra, M.; Drzal, L.T.; Selke, S.E.; Harte, B.R.; Hinrichsen, G. Natural fibers, biopolymers, and biocomposites: An introduction. In Natural Fibers, Biopolymers, and Biocomposites; Mohanty, A.K., Misra, M., Drzal, L.T., Eds.; CRC Press: Boca Raton, FL, USA, 2005.

95. Darder, M.; Aranda, P.; Ruiz-Hitzky, E. Bionanocomposites: A new concept of ecological, bioinspired, and functional hybrid materials. Adv. Mat. 2007, 19, 1309-1319.

96. Espert, A.; Vilaplana, F.; Karlsson, S. Comparison of water absorption in natural cellulosic fibres from wood and one-year crops in polypropylene composites and its influence on their mechanical properties. Compos. A-Appl. Sci. Manuf. 2004, 35, 1267-1276.

97. Gandini, A.; Belgacem, M.N. Chemical Modification of Wood. In Monomers, Polymers and Composites from Renewable Resources, 1st ed.; Gandini, A., Belgacem, M.N., Eds.; Elsevier: Oxford, UK, 2008; pp. 419-432.

98. Gandini, A.; Belgacem, M.N. The state of the art. In Monomers, Polymers and Composites from Renewable Resources, 1st ed.; Gandini, A., Belgacem, M.N., Eds.; Elsevier: Oxford, UK, 2008; pp. 1-16.

99. Pasquini, D.; Belgacem, M.N.; Gandini, A.; Curvelo, A.A.D. Surface esterification of cellulose fibers: Characterization by DRIFT and contact angle measurements. J. Colloid Interface Sci. 2006, 295, 79-83.

100. Tserki, V.; Zafeiropoulos, N.E.; Simon, F.; Panayiotou, C. A study of the effect of acetylation and propionylation surface treatments on natural fibres. Compos. A-Appl. Sci. Manuf. 2005, 36, 1110-1118.

101. Wambua, P.; Ivens, J.; Verpoest, I. Natural fibres: Can they replace glass in fibre reinforced plastics? Compos. Sci. Technol. 2003, 63, 1259-1264.

102. Favier, V.; Canova, G.R.; Cavaillé, J.-Y.; Chanzy, H.; Dufresne, A.; Gauthier, C. Nanocomposites materials from latex and cellulose whiskers. Polym. Adv. Technol. 1995, 6, 351-355.

103. Helbert, W.; Cavaille, J.Y.; Dufresne, A. Thermoplastic nanocomposites filled with wheat straw cellulose whiskers. Part I. Processing and mechanical behavior. Polym. Compos. 1996, 17, 604-611.

104. Kvien, I.; Oksman, K. Orientation of cellulose nanowhiskers in polyvinyl alcohol. Appl. Phys. A-Mat. Sci. Process. 2007, 87, 641-643.

105. Roohani, M.; Habibi, Y.; Belgacem, N.M.; Ebrahim, G.; Karimi, A.N.; Dufresne, A. Cellulose whiskers reinforced polyvinyl alcohol copolymers nanocomposites. Europ. Polym. J. 2008, 44, 2489-2498. 
106. Johnson, K.R.; Zink-Sharp, A.; Renneckar, S.H.; Glasser, W.G. A new bio-based nancomposite: fibrillated TEMPO-oxidazed celluloses in hydroxypropylcellulose matrix. Cellulose 2008, 16, 227-238.

107. Dubief, D.; Samain, E.; Dufresne, A. Polysaccharide microcrystals reinforced amorphous poly(beta-hydroxyoctanoate) nanocomposite materials. Macromolecules 1999, 32, 5765-5771.

108. Dufresne, A.; Kellerhals, M.B.; Witholt, B. Transcrystallization in Mcl-PHAs/cellulose whiskers composites. Macromolecules 1999, 32, 7396-7401.

109. Chazeau, L.; Cavaille, J.Y.; Canova, G.; Dendievel, R.; Boutherin, B. Viscoelastic properties of plasticized PVC reinforced with cellulose whiskers. J. Appl. Polym. Sci. 1999, 71, 1797-1808.

110. Chazeau, L.; Cavaille, J.Y.; Terech, P. Mechanical behaviour above T-g of a plasticised PVC reinforced with cellulose whiskers; A SANS structural study. Polymer 1999, 40, 5333-5344.

111. Chazeau, L.; Paillet, M.; Cavaille, J.Y. Plasticized PVC reinforced with cellulose whiskers. I. Linear viscoelastic behavior analyzed through the quasi-point defect theory. J. Polym. Sci. B 1999, 37, 2151-2164.

112. Terech, P.; Chazeau, L.; Cavaille, J.Y. A small-angle scattering study of cellulose whiskers in aqueous suspensions. Macromolecules 1999, 32, 1872-1875.

113. Ruiz, M.M.; Cavaille, J.Y.; Dufresne, A.; Graillat, C.; Gerard, J.F. New waterborne epoxy coatings based on cellulose nanofillers. Macromol. Symp. 2001, 169, 211-222.

114. Heux, L.; Bonini, C. Dispersion de microfibrilles et/ou de microcristaux, notamment de cellulose, dans un solvant organique. French Patent. FR2794762, 14 June 1999.

115. Marchessault, R.H.; Morehead, F.F.; Walter, N.M. Liquid crystal systems from fibrillar polysaccharides. Nature 1959, 184, 632-633.

116. Heux, L.; Chauve, G.; Bonini, C. Nonflocculating and chiral-nematic self-ordering of cellulose microcrystals suspensions in nonpolar solvents. Langmuir 2000, 16, 8210-8212.

117. Ljungberg, N.; Bonini, C.; Bortolussi, F.; Boisson, C.; Heux, L.; Cavaille, J.Y. New nanocomposite material reinforced with cellulose whiskers in atactic polypropylene: Effect of surface and dispersion cheracteristics. Biomacromolecules 2005, 6, 2732-2739.

118. Ljungberg, N.; Cavaille, J.Y.; Heux, L. Nanocomposites of isotactic polypropylene reinforced with rod-like cellulose whiskers. Polymer 2006, 47, 6285-6292.

119. Azizi Samir, M.A.S.; Alloin, F.; Sanchez, J.Y.; El Kissi, N.; Dufresne, A. Preparation of cellulose whiskers reinforced nanocomposites from an organic medium suspension. Macromolecules 2004, 37, 1386-1393.

120. Azizi Samir, M.A.S.; Alloin, F.; Sanchez, J.Y.; Dufresne, A. Cross-linked nanocomposites polymer eletrolytes reinforced with cellulose whiskers. Macromolecules 2004, 37, 4839-4844.

121. Viet, D.; Beck-Candanedo, S.; Gray, D.G. Dispersion of cellulose nanocrystals in polar organic solvents. Cellulose 2007, 14, 109-113.

122. van den Berg, O.; Capadona, J.R.; Weder, C. Preparation of homogeneous dispersions of tunicate cellulose whiskers in organic solvents. Biomacromolecules 2007, 8, 1353-1357.

123. Ly, B.; Thielemans, W.; Dufresne, A.; Chaussy, D.; Belgacem, M.N. Surface functionalization of cellulose fibres and their incorporation in renewable polymeric matrices. Compos. Sci. Technol. 2008, 68, 3193-3201. 
124. Nair, K.G.; Dufresne, A.; Gandini, A.; Belgacem, M.N. Crab shell chitin whiskers reinforced natural rubber nanocomposites. 3. Effect of chemical modification of chitin whiskers. Biomacromolecules 2003, 4, 1835-1842.

125. Gousse, C.; Chanzy, H.; Excoffier, G.; Soubeyrand, L.; Fleury, E. Stable suspensions of partially silylated cellulose whiskers dispersed in organic solvents. Polymer 2002, 43, 2645-2651.

126. Gousse, C.; Chanzy, H.; Cerrada, M.L.; Fleury, E. Surface silylation of cellulose microfibrils: Preparation and rheological properties. Polymer 2004, 45, 1569-1575.

127. Lin, N.; Chen, G.; Huang, J.; Dufresne, A.; Chang, P.R. Effects of polymer-grafted natural nanocrystals on the structure and mechanical properties of poly(lactic acid): A case of cellulose whiskers-graft-polycaprolactone. J. Appl. Polym. Sci. 2009, 113, 3417-3425.

128. Lönnberg, H.; Fogelström, L.; Samir, S.; Berglund, L.A.; Malmström, E.; Hult, A. Surface grafting of microfibrillated cellulose with poly( $\varepsilon$-caprolactone) - Synthesis and characterization. Europ. Polym. J. 2008, 44, 2991-2997.

129. Berlioz, S.; Molina-Boisseau, S.; Nishiyama, Y.; Heux, L. Gas-phase surface esterification of cellulose microfibrils and whiskers. Biomacromolecules 2009, 10, 2144-2151.

130. Halpin, J.C.; Kardos, J.L. Moduli of crystalline polymers emploing composites theory. J. Appl. Phys. 1972, 43, 2235-2241.

131. Takayanagi, M.; Uemura, S.; Minami, S. Application of equivalent model method to dynamic rheo-optical properties of a crystalline polymer. J. Polym. Sci. C 1964, 5, 113-122.

132. Ouali, N.; Cavaille, J.Y.; Perez, J. Elastic, viscoelastic and plastic behavior of multiphase polymer blends. Plast. Rubber Comp. Process. Appl. 1991, 16, 55-60.

133. Dufresne, A. Comparing the mechanical properties of high performances polymer nanocomposites from biological sources. J. Nanosci. Nanotechnol. 2006, 6, 322-330.

134. Dufresne, A.; Vignon, M.R. Improvement of starch film performances using cellulose microfibrils. Macromolecules 1998, 31, 2693-2696.

135. Leitner, J.; Hinterstoisser, B.; Wastyn, M.; Keckes, J.; Gindl, W. Sugar beet cellulose nanofibril-reinforced composites. Cellulose 2007, 14, 419-425.

136. Seydibeyoglu, M.O.; Oksman, K. Novel nanocomposites based on polyurethane and micro fibrillated cellulose. Compos. Sci. Technol. 2008, 68, 908-914.

137. Wu, Q.J.; Henriksson, M.; Liu, X.; Berglund, L.A. A high strength nanocomposite based on microcrystalline cellulose and polyurethane. Biomacromolecules 2007, 8, 3687-3692.

138. Nakagaito, A.N.; Fujimura, A.; Sakai, T.; Hama, Y.; Yano, H. Production of microfibrillated cellulose (MFC)-reinforced polylactic acid (PLA) nanocomposites from sheets obtained by a papermaking-like process. Compos. Sci. Technol. 2009, 69, 1293-1297.

139. Angles, M.N.; Dufresne, A. Plasticized starch/tunicin whiskers nanocomposites. 1. Structural analysis. Macromolecules 2000, 33, 8344-8353.

140. Azizi Samir, M.A.S.; Alloin, F.; Sanchez, J.Y.; Dufresne, A. Cellulose nanocrystals reinforced poly(oxyethylene). Polymer 2004, 45, 4149-4157.

141. Lu, Y.S.; Weng, L.H.; Cao, X.D. Biocomposites of plasticized starch reinforced with cellulose crystallites from cottonseed linter. Macromol. Biosci. 2005, 5, 1101-1107.

142. Mathew, A.P.; Dufresne, A. Morphological investigation of nanocomposites from sorbitol plasticized starch and tunicin whiskers. Biomacromolecules 2002, 3, 609-617. 
143. Morin, A.; Dufresne, A. Nanocomposites of chitin whiskers from Riftia tubes and poly(caprolactone). Macromolecules 2002, 35, 2190-2199.

144. Petersson, L.; Mathew, A.P.; Oksman, K. Dispersion and properties of cellulose nanowhiskers and layered silicates in cellulose acetate butyrate nanocomposites. J. Appl. Polym. Sci. 2009, 112, 2001-2009.

145. Syverud, K.; Stenius, P. Strench and barrier properties of MFC films. Cellulose 2009, 16, 75-85.

146. Svagan, A.J.; Hedenqvist, M.S.; Berglund, L. Reduced water vapor sorption in cellulose nanocomposites with starch matrix. Comp. Sci. Technol. 2009, 69, 500-506.

147. Fukuzumi, H.; Saito, T.; Iwata, T.; Kumamoto, Y.; Isogai, A. Transparent and high gas barrier films of cellulose nanofibers prepared by TEMPO-mediated oxidation. Biomacromolecules 2009, $10,162-165$.

148. Petersson, L.; Oksman, K. Biopolymer based nanocomposites: Comparing layered silicates and microcrystalline cellulose as nanoreinforcement. Comp. Sci. Technol. 2006, 66, 2187-2196.

149. Kristo, E.; Biliaderis, C.G. Physical properties of starch nanocrystal-reinforced pullulan films. Carbohyd. Polym. 2007, 68, 146-158.

150. Saxena, A.; Ragauskas, A.J. Water transmission barrier properties of biodegradable films based on cellulosic whiskers and xylan. Carbohyd. Polym. 2009, 78, 357-360.

(C) 2010 by the authors; licensee MDPI, Basel, Switzerland. This article is an open access article distributed under the terms and conditions of the Creative Commons Attribution license (http://creativecommons.org/licenses/by/3.0/). 